\title{
Effects of Resveratrol Supplementation on Glycemic Response and Oxidant Status in Moderately Exercised Mature Quarter Horse Geldings
}

Jennie L. Zambito

West Virginia University

Follow this and additional works at: https://researchrepository.wvu.edu/etd

\section{Recommended Citation}

Zambito, Jennie L., "Effects of Resveratrol Supplementation on Glycemic Response and Oxidant Status in Moderately Exercised Mature Quarter Horse Geldings" (2011). Graduate Theses, Dissertations, and Problem Reports. 3333.

https://researchrepository.wvu.edu/etd/3333

This Thesis is protected by copyright and/or related rights. It has been brought to you by the The Research Repository @ WVU with permission from the rights-holder(s). You are free to use this Thesis in any way that is permitted by the copyright and related rights legislation that applies to your use. For other uses you must obtain permission from the rights-holder(s) directly, unless additional rights are indicated by a Creative Commons license in the record and/ or on the work itself. This Thesis has been accepted for inclusion in WVU Graduate Theses, Dissertations, and Problem Reports collection by an authorized administrator of The Research Repository @ WVU. For more information, please contact researchrepository@mail.wvu.edu. 


\title{
Effects of Resveratrol Supplementation on Glycemic Response and Oxidant Status
} in Moderately Exercised Mature Quarter Horse Geldings

\author{
Jennie L. Zambito \\ Thesis submitted to the \\ Davis College of Agriculture, Natural Resources and Design \\ at West Virginia University \\ in partial fulfillment of the requirements \\ for the degree of \\ Master of Science \\ in

\section{Animal and Nutritional Sciences} \\ Holly S. Spooner, Ph. D., Chair \\ Eugene E. Felton, Ph. D. \\ Janet C. Tou, Ph. D. \\ Division of Animal and Nutritional Sciences \\ Morgantown, West Virginia \\ 2011
}

Keywords: Horse, Glucose, Exercise, Resveratrol, Oxidative Stress 


\section{ABSTRACT \\ Effects of Resveratrol Supplementation on Glycemic Response and Oxidant Status in Moderately Exercised Mature Quarter Horse Geldings}

\section{Jennie L. Zambito}

Resveratrol, a naturally occurring phytocompound is known to exert numerous health benefits including improved insulin sensitivity and glucose tolerance, along with decreased tissue damage due to reactive oxygen species (ROS). This compound is incorporated in a multitude of supplements targeted to performance horses, yet no research in an athletic equine model has been completed to date. Therefore, this study was performed to test the hypothesis that resveratrol supplementation would improve glucose tolerance and insulin sensitivity, while reducing oxidant damage in an exercising model. Six, healthy, fit aged $(10.5 \pm 1.5 \mathrm{yr}, \sim 500 \mathrm{~kg})$ Quarter Horse geldings were assigned to three treatment groups in a Latin Square random crossover design with one week between crossovers. Horses either received no supplementation (control, C) or one of two treatments $(\mathrm{T})$; low dose $(\mathrm{L}, 2.5 \mathrm{~g}$ of trans-resveratrol) and high dose $(\mathrm{H}, 5 \mathrm{~g}$ of transresveratrol) administered on a daily basis for 14 days. Body weights (BW), blood samples, and muscle biopsies were collected on day 0 and day 14 of each supplementation period. All horses were moderately exercised 3 times a week for 60 minutes with an average heart rate of $90 \mathrm{bpm}$. A frequently sampled intravenous glucose tolerance test (FSIGT) was conducted on day 10 of supplementation during each treatment period. Feed intake data was collected daily. Samples from day 0 and 14 were analyzed for thiobarbituric acid reactive substances (TBARS), while FSIGT samples were analyzed for plasma insulin and glucose. The null hypothesis was rejected when $\mathrm{P}<0.05$, and trends were identified when $\mathrm{P}<0.10$. Minimal model analysis of FSIGT, along with evaluation of baseline inulin and glucose concentrations, and area under the glucose and insulin curve showed no effect of resveratrol supplementation $(\mathrm{P}>0.05)$. Plasma TBARS was unaffected by resveratrol supplementation $(\mathrm{P}>0.05)$ within this model. Body weight did not change due to $\mathrm{T}$, yet contrast between $\mathrm{C}$ and $\mathrm{T}$ displayed trends toward increased feed intake as $\% \mathrm{BW}$ of both hay and concentrate $(\mathrm{P}<0.10)$. In conclusion, resveratrol supplementation in the moderately exercised horse does not improve insulin sensitivity or glucose tolerance, or overall lipid peroxidation. Increased feed intake displayed by $\mathrm{T}$ over $\mathrm{C}$ may have a potential application for a high performance animal. These observations display a need to further evaluate the effects of resveratrol in other equine models, and a more in depth assessment of resveratrol within the athletic horse. 


\section{ACKNOWLEDGEMENTS}

Initially, I would like to thank my funding sources for my project; West Virginia University Faculty Senate Grants for Research and Scholarship and the West Virginia University Summer Undergraduate Research Experience Program.

Foremost, I would like to thank my advisor, Dr. Holly Spooner, for her mentoring and guidance through the completion of my masters degree. Her support began with her belief in me as a student, and has been unfailing through the duration of my time at WVU. I am very fortunate to have found an advisor with whom I have formed a unique relationship with, and I look forward to continuing to study with her in the upcoming years.

The research presented in this manuscript would not have been possible without the aid of numerous people. I would like to thank Dr. Carey Williams, Dr. Gene Felton, and Dr. Janet Tou for their guidance, input and review of the project as my committee members. Due to the intensity of data collection during this study, numerous friends and students were recruited. Scott Spooner was a tremendous help in all aspects of this project, and I am so thankful for his assistance. Ashley Campasino, Kaitlyn Street, Todd Ramboldt, Erin Carver, Lousia Bowen, Charlie Rimer, Colton Prudnick, and numerous others aided in the collection of my samples and data. Without their combined efforts, the study would have been impossible to complete.

Lastly, I would like to thank my friends and family for all their support, encouragement and belief in me. My family has always instilled in me the belief that I am capable of anything through hard work and determination. Their support from miles away 
was equally as important in the completion of this project as those working beside me, and for that I am truly grateful. 


\section{TABLE OF CONTENTS}

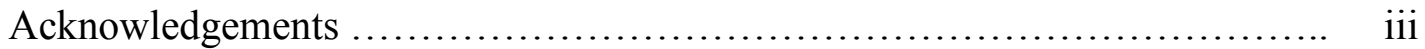

Table of Contents ........................................................ v

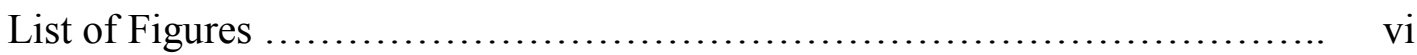

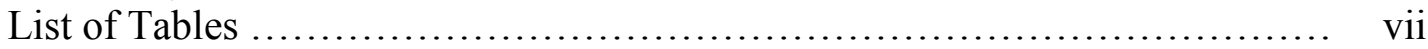

Introduction ......................................................... 1

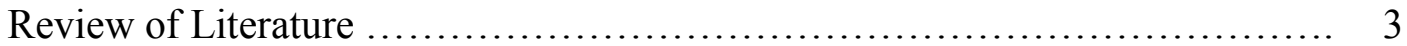

I. The Athletic Horse .......................................... 3

a. Aerobic Capacity ...................................... 3

b. Energy Storage .......................................... 4

II. Equine Glucose Metabolism .................................... 5

a. Digestion and Absorption ............................... 6

b. Glycogen Storage and Usage .............................. 6

III. Glucose Homeostasis .......................................... 7

a. Glycemic Response ................................... 8

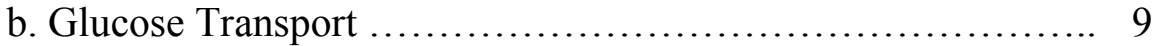

c. Insulin Sensitivity and Effectiveness .......................... 9

d. Measuring Insulin Sensitivity in Horses ...................... 11

e. Factors Affecting Insulin Sensitivity ....................... 18

IV. Effects of Exercise on Glucose Metabolism ......................... 22

a. Acute Exercise .............................................. 22

b. Exercise Training ........................................ 24

c. The Exercising Equine Model ................................... 24

V. Effects of Exercise on Oxidant Status ............................. 26

a. Reactive Oxygen Species Production ......................... 26

b. Functions of Reactive Oxygen Species ......................... 28

c. Detection Methods ........................................... 29

VI. Resveratrol ...................................................... 30

a. Synthesis and Structure ...................................... 32

b. Bioavailability and Metabolism ............................... 33

c. Functions .......................................................... 36

d. Dosage ......................................................... 39

e. Resveratrol in the Equine Industry ......................... 41

Statement of Problem and Objectives ..................................... 42

Materials and Methods .................................................... 43

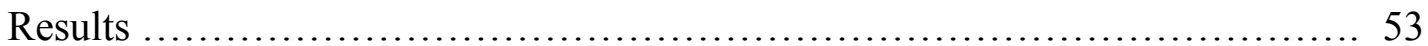

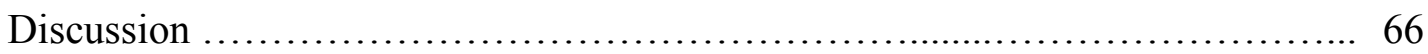

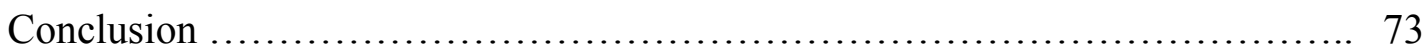

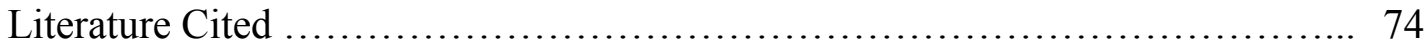

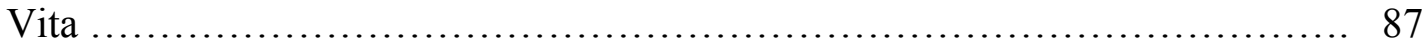

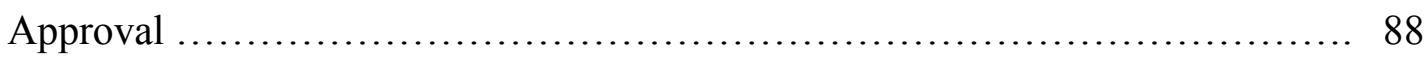




\section{LIST OF FIGURES}

Figure $\quad$ Page

1. Diagram of Minimal Model Compartments ............................ 17

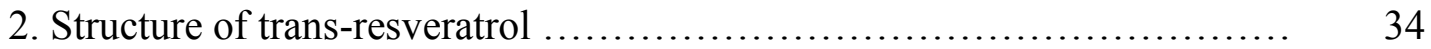

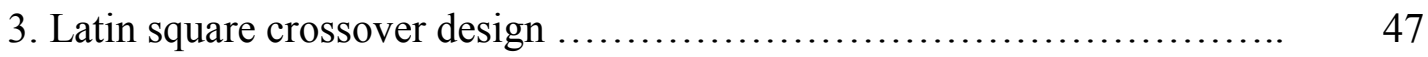

4. Hay intake as $\%$ body weight, treatment $\ldots \ldots \ldots \ldots \ldots \ldots \ldots \ldots \ldots \ldots \ldots . \ldots \ldots$

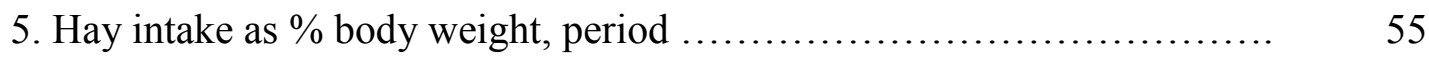

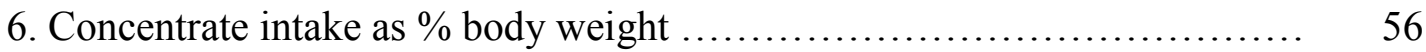

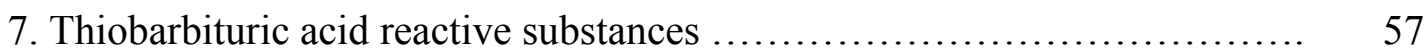

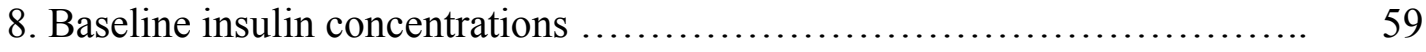

9. Baseline glucose concentrations .................................... 60

10. Control frequently sampled intravenous glucose tolerance test insulin and glucose curves................................................ 61

11. Low dose resveratrol supplementation frequently sampled intravenous glucose tolerance test insulin and glucose curves ..................... 62

12. High dose resveratrol supplementation frequently sampled intravenous glucose tolerance test insulin and glucose curves ...................... 63

13. Basal glucose concentrations, a Minimal Model parameter ............... 64 


\section{LIST OF TABLES}

Table Page

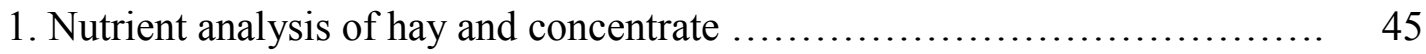

2. Exercise protocol $\ldots \ldots \ldots \ldots \ldots \ldots \ldots \ldots \ldots \ldots \ldots \ldots \ldots \ldots \ldots \ldots \ldots \ldots \ldots \ldots \ldots \ldots \ldots \ldots, \quad 48$

3. Least square means of Minimal Model parameters and area under glucose

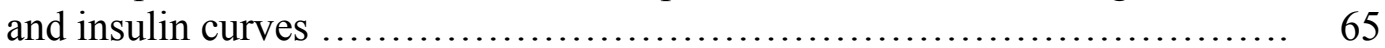




\section{INTRODUCTION}

The horse is an extraordinary athlete subjected to numerous stressors during the course of exercise, including oxidative stress and inflammation. During exercise, oxidation of energy substrates is critical to provide the working muscles with enough fuel to complete the desired task. As the rate of oxidation increases, the production of reactive oxygen species, specifically free radicals, also increases. Damage to vital tissues are caused by free radicals, by destroying cell proteins, fatty acids and DNA ${ }^{1}$ which can result in lameness and an inability to perform due to muscle soreness in horses. Antioxidants naturally occurring within the body or supplemented in the diet aid in protecting the tissues from the damaging effects of free radicals by inhibiting production or up-regulating degradation of free radicals as well as by promoting repair of damaged cells or tissues. $^{2}$

At the same time, metabolic syndrome and insulin resistance have been well characterized in both performance and non-athletic horses. Insulin resistance has been implicated in the development of debilitating disorders including laminitis and osteochondritis $^{3}$ and is linked to the upregulation of inflammatory pathways.

Both nutritional and exercise interventions are being researched for their ability to lower insulin resistance while acting as an antioxidant. Resveratrol (trans-3, 4', 5trihydroxystilbene), a phytocompound present in grapes, red wine, yucca, and peanuts, ${ }^{4-6}$ has been found to act as a powerful antioxidant and anti-inflammatory agent, along with beneficial effects against ageing and metabolic diseases. ${ }^{7}$ The anti-inflammatory and antioxidant characteristics of resveratrol have been studied within rodent and human 
models ${ }^{4-6,8,9}$ however, research in an equine model is severely lacking. Many nutritional supplements fed to performance horses today contain resveratrol, yet information on the efficacy of the compound to impact the glycemic response, inhibit the effects of free radicals, and reduce inflammation is unknown. A better understanding of how resveratrol contributes to equine health and potential performance could be obtained by evaluating various parameters relating to glycemic response and levels of oxidative damage. This data can then be utilized as preliminary evidence to support the use of resveratrol supplementation in performance horses or in horses suffering from equine metabolic syndrome or insulin resistance. 


\section{CHAPTER I: LITERATURE REVIEW}

\section{The Athletic Horse}

The horse is an extraordinary athlete, due to a compilation of physiologic adaptations utilized to increase performance. From a survival standpoint, enhanced speed was necessary to escape predators, and increased endurance was required to travel long distances to find food or water. Through the domestication of horses, humans were able to utilize this athleticism for work, travel and leisure. The various breeds are utilized for the areas in which they excel, yet all horses display an ability to run and jump at a much higher level than other animals of similar body size. This enhanced athletic ability of the horse is due to high maximal aerobic capacity, large intramuscular energy stores, high mitochondrial concentration in the muscle, efficiency of gait, and efficient thermoregulation. ${ }^{10}$ All play an integral role in the superior athletic ability displayed by the horse, yet for the purpose of this review, only factors influencing aerobic capacity and metabolism will be discussed in detail.

\section{Aerobic Capacity}

Aerobic capacity encompasses oxygen transport, and movement of oxygenated blood to the peripheral tissues for use, and the utilization of oxygen at the muscle. The large aerobic capacity in the horse is primarily due to large maximum cardiac output and higher hemoglobin concentration. ${ }^{10}$ Cardiac output is defined as the product of heart rate and stroke volume, and is responsible for the amount of blood delivered to the tissues. At times of increased oxygen needs, heart rate and stroke volume can increase to partially compensate for the deficit, but other mechanisms must be recruited to match the body's needs. 
Oxygen transport depends on the ability to move oxygen from the air to the peripheral tissues efficiently. The circulation is responsible for moving oxygenated blood from the lungs to the tissues for delivery at a level contingent upon the oxygen carrying capacity of the blood. During exercise, when the need for oxygen in the working muscles is elevated, the horse increases the amount of circulating red blood cells via splenic contraction without a simultaneous increase in plasma volume. ${ }^{11}$ This increase in red blood cells, and thereby hemoglobin, increases the oxygen carrying capacity of arterial blood by up to $50 \%$ during intense exercise. ${ }^{3}$ By increasing the amount of oxygen carried within the blood, greater amounts of oxygen can be unloaded at the tissues and utilized.

Oxygen utilization is achieved during aerobic respiration within the mitochondria. Facilitation of increased oxygen delivery to the muscle is achieved by high capillary and mitochondrial density, which maximize the effects of increased cardiac output and splenic contraction. ${ }^{12}$ Mitochondria are responsible for providing energy to the working muscle cell, and therefore the greater quantity of mitochondria within the muscle, the greater the oxidative ability of the tissue. When provided with adequate substrate and optimal oxygen delivery, aerobic capacity of the horse is far superior to other animals of similar size and stature. ${ }^{10}$

\section{Energy Storage}

Oxidation of carbohydrates and fats provides the main source of chemical energy for both resting and working cells. Glucose, an absorbable unit of simple carbohydrate metabolism is stored as glycogen within the liver and muscle, with over $90 \%$ of total body carbohydrate stored within the muscle in horses. ${ }^{7}$ Movement of glucose from the circulation into the cell via insulin signaling is needed to facilitate synthesis of glycogen 
and storage for later oxidation into ATP. High intramuscular concentration of energy substrates are important for fueling muscle during exercise, as the movement of glucose from blood into the muscle and consequently into the mitochondria is only slightly $(<10 \%)$ responsible for the energy utilized during intense exercise. ${ }^{13}$ Glucose metabolism within the muscle differs between fiber types and work load, therefore the entry of glucose into the cell is crucial for all types of exercise.

\section{Equine Glucose Metabolism}

The horse utilizes a range of hydrolyzable and fermentable forage carbohydrates as its main source of energy. Pasture is the most common form of habitat and nutrition for the horse, however in areas where pasture cannot meet the horse's nutrient needs such as during times of extreme weather, hay, or preserved pasture is often used. Forage must be fed at a minimum of $1 \%$ of the horse's body weight per day, and often can be fed at an amount to meet the horse's maintenance energy requirements. ${ }^{14}$ Approximately $75 \%$ of plant matter is carbohydrate, which can be divided into two main categories: nonstructural carbohydrates (NSC), and structural carbohydrates. ${ }^{14}$ It is important to consider the seasonal variation of carbohydrate content in pasture when feeding, as supplementation or dietary restriction may be necessary for proper maintenance. As forages mature from leafy to stemmy stages, the proportion of non-structural carbohydrates (such as disaccharides, some oligosaccharides and starch equivalents, like fructans) to structural carbohydrates (such as hemicellulose and cellulose) is reduced. ${ }^{15}$ Eating large amounts of feedstuffs high in NSCs may cause spillover of non-structural 
carbohydrates into the hind gut, where microbial fermentation of these nutrients can be detrimental to the horse.

\section{Digestion and Absorption}

Digestion and absorption of the non-structural carbohydrates should occur in the small intestine. Numerous factors can affect prececal digestibility, such as source, processing and amount of starch present, timing of forage feeding, and individual differences between horses. ${ }^{14}$ Initially, gastric acid in the stomach begins carbohydrate hydrolysis independent of enzyme activity. Digesta then moves to the small intestine, where further digestion is achieved via pancreatic $\alpha$-amylase, and amylopectinase cleave $\alpha-1,4$ and $\alpha-1,6$ linkages of amylose and amylopectin respectively, producing disaccharides and oligosaccharides. ${ }^{15}$ These products are then subjected to disaccharidases sucrase, lactase and maltase in the brush border, which result in the liberation of glucose, fructose and galactose for absorption. ${ }^{16}$ Glucose absorption occurs along the brush border via the $\mathrm{Na}+$ /glucose cotransporter type 1 (SGLT1) moving glucose into the enterocyte, and facilitative glucose transporters (GLUT) which transport

glucose through the basement membrane and into the circulation. ${ }^{17,18}$ For the purpose of this review, the effects of glucose in the central circulation and uptake into the tissues will be discussed later in detail due to the effects of glucose concentration on insulin release. Fructose and galactose do not play an integral role in this response, and therefore will not be discussed, although it is important to recognize their presence and need in metabolic homeostasis. 
Glycogen Storage and Usage

Upon entry into the liver or muscle, glucose can either be stored as glycogen, or oxidized as a source of energy for immediate use. Entry into either pathway requires glucose to first be phosphorylated into glucose-6-phosphate (G6P) by hexokinase or glucokinase in the muscle and liver, respectively. If the body is in a fed state, where energy substrates are high, G6P will enter the glycogen synthesis pathway. Main chain $\alpha-$ 1,4 linkages between glucose residues are formed via glycogen synthase, and the $\alpha-1,6$ branch points are formed by glycogen branching enzyme. ${ }^{19}$ The branched structure of glycogen allows for increased solubility and to increase the number of reducing ends that are able to react with glycogen synthase and phosphorylase.

Glucose molecules will continue to be added to glycogen in the postprandial state until glucose and insulin concentrations begin to fall. At this time, glucagon is released, and glucose can be liberated from glycogen in both the muscle and the liver via the action of glycogen phosphorylase and glycogen debranching enzyme. ${ }^{19}$ Although the general concept is the same, the removal of glucose from storage has differing purposes across the tissues. Liver glycogen stores are used to maintain blood glucose; therefore, when glucose levels drop, G6P is dephosphorylated by glucose-6-phosphatase, and enters the bloodstream. ${ }^{19}$ Muscle lacks this enzyme, and glucose freed from glycogen will remain in the muscle cell, and must be used for intracellular energy.

\section{Glucose Homeostasis}

Hormonal regulation is central to maintaining blood glucose concentrations at a relatively constant level. A balance between insulin, glucagon and other hormones are 
necessary to metabolic homeostasis. Normal equine blood glucose concentration should be within the range of $40-70 \mathrm{mg} / \mathrm{dL},{ }^{20}$ and an inability to maintain this basal level could result in a multitude of detrimental changes to overall homeostasis within the body. For example, prolonged elevation of glucose concentrations has a toxic effect on cells, ${ }^{21}$ whereas low concentrations can produce seizures and disorientation. ${ }^{22}$

The effects of these hormones reach far beyond their role in glucose metabolism, and many intermediates within these pathways feed into other catabolic and anabolic states. A prolonged period of fed or fasting metabolism can cause obesity, and insulin resistance, or starvation, respectively. Achievement of optimal body condition, performance and physiologic mechanisms is possible with proper management and understanding of the detailed hormone functions within these systems.

\section{Glycemic Response}

The ability for a feedstuff to be hydrolyzed, absorbed and released into circulation to elevate blood glucose concentration is generally regarded as the glycemic index of a feed. ${ }^{15}$ The time needed for these steps to occur is different among various feeds, and can be affected by processing methods, which impact the ability for digestive carbolytic enzymes to contact the various polysaccharides within the feed. ${ }^{15}$ A feedstuff with a lower glycemic index will release glucose slowly into the bloodstream over time, whereas a high glycemic index feed will release glucose rapidly, causing blood glucose concentrations to spike. Any increase in blood glucose concentration above baseline concentrations will elicit an insulin release from the pancreas, which is aimed to decrease glucose concentrations back to baseline; however, repeated, rapid peaks in glucose and insulin can pose health concerns. ${ }^{15,16}$ 
Upon elevation of blood glucose concentration, glucose is transported into the pancreatic $\beta$ cell via facilitated diffusion by an insulin independent transporter, GLUT 2 . The degree to which blood glucose concentration is elevated will be proportionally displayed within the pancreatic $\beta$ cell, and thus will elicit an appropriately large response. ${ }^{23}$ Simply stated, membrane depolarization occurs in response to glucose entry, leading to intracellular calcium release, signaling the release of insulin-containing secretory vesicles via exocytosis. ${ }^{23}$ Insulin is then able to reach its target tissues via circulation, and elicit glucose uptake into the muscle and adipose tissues to reduce blood glucose concentrations.

\section{Glucose Transport}

Glucose transport is the rate limiting step of glucose metabolism at the skeletal muscle level. ${ }^{22}$ When insulin reaches the muscle, the hormone binds to the insulin receptor, composed of two $\alpha$ and two $\beta$ subunits, attached by a disulfide linkage, resulting in insulin receptor substrate tyrosine kinase activity. ${ }^{24}$ The insulin receptor phosphorylates several intracellular targets which serve as docking sites; the insulin receptor substrate family (IRS). These proteins act as a docking site for phosphatidylinositol-3 kinase (PI3K), and upon activation, PI3K functions to convert phosphatidylinositol-2-phopshate (PIP2) to phosphatidylinositol-3-phosphate (PIP3). ${ }^{25}$ Then, PIP3 activates protein kinase B, which functions to recruit vesicles containing GLUT 4 to the plasma membrane. ${ }^{25}$ Facilitated diffusion of glucose can then occur into the cell, and in turn will aid in the decrease of blood glucose concentration. The GLUT 4 isoform is considered to be an insulin dependent transporter, ${ }^{26}$ due to its reliance on hormone signaling to move the transporter to the membrane. The ability for insulin to 
elicit this response within the cell is dependent on the receptor's sensitivity to insulin, along with the effectiveness of promoting the GLUT 4 translocation to the cell surface.

\section{Insulin Sensitivity and Effectiveness}

Proper insulinemic response requires both sensitivity of the insulin receptor, and movement of GLUT4 to the membrane to facilitate glucose movement into the cell. Impairments to either portion of this pathway can cause prolonged, increased levels of circulating glucose, leading to an array of health concerns including insulin resistance. ${ }^{27}$ Determining an animal's ability to dispose of glucose at a normal rate is dependent on pancreatic responsiveness and insulin sensitivity. ${ }^{28}$ Understanding the mechanics behind glucose tolerance can allow for determination of various supplements, exercise training and disease effects on the individual parameters involved in this response.

Pancreatic responsivity is defined as the ability of pancreatic $\beta$-cells to secrete insulin in response to glucose stimuli. ${ }^{28}$ Inability of glucose to elicit an insulin response with enough amplitude to return glucose back to baseline levels can be viewed as impairment in this signaling pathway. It is important, however, to note that diminution of the insulin response may be due to rapid insulin degradation or neutralization by antibodies before the hormone can make contact with its receptor and not due to pancreatic responsiveness to stimuli. ${ }^{29}$

Insulin sensitivity is determined by the effect of insulin at the cellular level. Interaction of the hormone with its receptor elicits the aforementioned cascade utilized to bring glucose into the muscle and adipose tissue. Inability of insulin to elicit this response may be caused by unresponsiveness of the receptor or an inability to properly translocate 
sufficient GLUT4 to the membrane surface, and subsequent decrease in intracellular glucose use. ${ }^{27,29}$ Whole body glucose tolerance is affected by the amount of insulin secreted by the pancreas in response to glucose and sensitivity of the skeletal muscle to insulin; therefore, both parameters need to be assessed together to gain a full understanding of glucose homeostasis.

\section{Measuring Insulin Sensitivity in Horses}

Development of an accurate means of measuring and evaluating the relationship between glucose and insulin has progressed from a simplistic approach to a comprehensive picture. Initially, single, fasting glucose and insulin measurements were used to identify any imbalance in these systems. ${ }^{29}$ Accuracy of this method was questioned due to individual variation of these concentrations in a short period as a result of stress, feeding or diurnal variation. ${ }^{29,30}$ Ratios of basal glucose-to-insulin have also been utilized, where glucose-to-insulin ratios describe insulin sensitivity, and insulin-toglucose ratios describe pancreatic responsiveness to blood glucose. ${ }^{30}$ Tolerance testing is also implemented to gain an integrated understanding of in vivo response to bolus glucose doses, exogenous insulin injection, and the combined effect of both on glucose homeostasis.

Oral glucose tolerance tests (OTT) are best utilized to assess small intestinal absorption of glucose, resulting in hepatic glucose uptake and the endogenous release of insulin into the body. Utilization of this test should be implemented to address issues of malabsorption in the small intestine, and to a limited extent, endocrine function of the pancreas and target tissue insulin resistance. ${ }^{31-34}$ In brief, the test is conducted after an overnight fast, and a dose of $1 \mathrm{~g} / \mathrm{kg} \mathrm{BW}$ glucose is administered via nasogastric tube. 
Blood samples are then taken at various timepoints between 0 and 360 min, with peak glucose concentration occurring between 90 and 120 min post dosage, and baseline concentrations re-established after 4 to $6 \mathrm{~h} \cdot{ }^{31,35,36}$ Decreased response to glucose in comparison to normal values may suggest reduced pancreatic function; ${ }^{36}$ however, it is important to consider possible shortcomings of this procedure. Stress of nasogastric intubation, delayed gastric emptying, variation in glucose administration rate, and reduced intestinal absorption may also impact the validity of the test results. ${ }^{29,36}$

Intravenous glucose tolerance testing has been widely used to evaluate the differences between diet, breed and disease states of various equids. ${ }^{37-39}$ The variable effect of glucose absorption by the digestive tract as seen in the OTT is eliminated in the intravenous glucose tolerance test (IVGT) ${ }^{29}$ The test is conducted by infusing $0.5 \mathrm{~g}$ glucose $/ \mathrm{kg}$ BW directly into the bloodstream of a fasted animal over a short period of time, and collecting blood samples at various timepoints over 5 to $6 \mathrm{~h}$ post bolus glucose administration. Glucose utilization and thereby insulin sensitivity can be calculated relative to glucose half-life and fractional turnover rate. ${ }^{35}$ Normal horses should display peak glucose concentrations around 15 min after infusion, ${ }^{30}$ and return to baseline approximately one hour after the start of the test. ${ }^{22}$ Insulin response should parallel glucose response curves, where peak insulin concentration should be seen 30 min post glucose dose ${ }^{36}$ Horses displaying a higher peak glucose concentration, delayed return to baseline glucose concentration may be due to impaired insulin release or inhibited glucose disposal. ${ }^{30}$ Unfortunately, with this test, it is only possible to determine if impaired pancreatic $\beta$-cell function is occurring by evaluation of serum insulin concentrations. Evaluation of tissue level sensitivity must be evaluated by other means. 
Insulin tolerance tests (ITT) are utilized to assess tissue sensitivity to insulin and evaluate the animal's response to hypoglycemia induced by the exogenous insulin dose. ${ }^{22,}$ ${ }^{30}$ Dosages range between 0.2 to $0.6 \mathrm{IU} / \mathrm{kg} \mathrm{BW}$, causing an approximate $50 \%$ drop in blood glucose from starting values within 20 to 30 min post dose, and a return to fasting values within 2 h. ${ }^{35,40}$ If any impairment is present within the test animal, glucose concentrations will not fall as dramatically, and return to fasting glucose level will be achieved at a faster rate. ${ }^{20,31}$ Results of this test are not a comprehensive representation of glucose homeostasis as it only address insulin function at the tissue level, and ability for the body to recover from hypoglycemia induced by a bolus insulin dose.

In all of the above methods, endogenous insulin can fluctuate freely, and thus may have an impact on glucose homeostasis during the test. A clamp technique was developed in 1966 allowing for plasma glucose to be manipulated to a desired concentration, thereby interrupting the negative feedback cycle through which glucose-insulin signaling occurs. ${ }^{44}$ Although this places the animal in a non-physiologic environment, it currently remains the most accurate tool used to determine the effects of hyperglycemia and hyperinsulinemia on various tissues and pathways affected by these states. ${ }^{22,29,27,30,36,41 \text {, }}$ 42 The hyperglycemic clamp causes an acutely elevated glucose concentration held constant at a predetermined level to suppress hepatic gluconeogenesis for the duration of the test. Glucose infusion rate is therefore a measure of insulin secretion and therefore can be utilized to quantify $\beta$ cell sensitivity to glucose. ${ }^{22,31}$ The hyperinsulinemic euglycemic clamp supplies steady state insulin concentration during which the rate of glucose infusion needed to maintain euglycemia displays insulin effectiveness at the target tissues. Both types of clamp provide a unique set of information to aid in the 
understanding of cellular glucose dynamics, yet a model to encompass physiologic responses to glucose tolerance is also useful.

Frequently sampled intravenous glucose tolerance tests (FSIGT) combines the theories described in the intravenous glucose and insulin tolerance tests by evaluating pancreatic insulin secretion and tissue sensitivity in a physiologically relevant situation. Procedure for this test involves rapid intravenous infusion of a bolus glucose dose at $0.33 \mathrm{~g} / \mathrm{kg} \mathrm{BW},{ }^{43}$ followed by an exogenous intravenous insulin dose at $30 \mathrm{mIU} / \mathrm{kg}$ of BW 20 min post glucose dose. ${ }^{20}$ The goal of this insulin infusion is to elicit a physiological, not pharmacological insulin effect, without inducing hypoglycemia. ${ }^{20,44}$ Simulation of plasma glucose changes when insulin effects are applied can then be utilized to determine insulin sensitivity. ${ }^{45}$ Frequent blood samples are taken after each respective dose, and analyzed for glucose and insulin concentrations for later analysis through the Minimal Model program (MinMod Millennium).

The Minimal Model program is designed to calculate variables used to describe factors mediating glucose homeostasis. This analytical model has been validated within the horse to evaluate normal versus disease states, ${ }^{28,43-46}$ and can be utilized to differentiate between insulin resistance with or without pancreatic compensation. ${ }^{29}$ Interpretation of glucose and insulin dynamics can be accomplished with the use of two mathematical models ${ }^{47}$ representative of the effect of insulin to increase glucose uptake and the effect of glucose to enhance insulin secretion. ${ }^{28}$ The insulin kinetics model breaks down insulin responsiveness to glucose, ${ }^{48}$ while the glucose kinetics model utilizes the insulin time course response to predict glucose kinetics, thus resulting in a measure of insulin sensitivity.$^{47}$ Parameters of the minimal model of glucose and insulin dynamics 
consist of insulin sensitivity $(\mathrm{Si})$, glucose effectiveness $(\mathrm{Sg})$, acute insulin response to glucose (AIRg) and disposition index (DI), ${ }^{20,49}$ which can be determined by fitting of glucose and insulin curves resulting from the FSIGT. Figure 1 describes the various compartments used within the minimal model concept to quantify $\mathrm{Si}, \mathrm{Sg}, \mathrm{AIRg}$, and DI. $^{20,49-51}$ Five main equations are used to determine these values, all which can be calculated using the minimal model. ${ }^{20,50,51}$

Glucose effectiveness is an expression of the capacity for glucose to mediate its own disposal independent of any insulin concentration change. ${ }^{20,49-51}$ This value can be calculated using the following equation:

$$
G^{\prime}(t)=-(X+S g) \times G(t)+(S g \times G b)
$$

where $G^{\prime}(t)$ represents rate $\left(\mathrm{min}^{-1}\right)$ of glucose clearance from plasma; X represents insulin action or the ability for insulin to accelerate glucose disposal at increased levels; $G(t)$ represents plasma glucose concentration $(\mathrm{mg} / \mathrm{dL})$ at time $\mathrm{t}$, where $\mathrm{G}(0)$ is the theoretical glucose concentration at time 0 ; and Gb represents basal glucose concentration $(\mathrm{mg} / \mathrm{dL})$ as maintained by hepatic production. ${ }^{20}$

Insulin sensitivity $\left(\mathrm{L} \cdot \mathrm{mU}^{-1} \cdot \mathrm{min}^{-1}\right)$ values are used to determine the capacity of insulin to promote glucose uptake. ${ }^{20}$ Use of the following equations gives a Si value:

$$
\begin{gathered}
X^{\prime}(t)=-p_{2} \times X(t)+\left(p_{3} \times[I(t)-I b]\right) \\
S i=p_{3} / p_{2}
\end{gathered}
$$

where $X^{\prime}(t)\left(\mathrm{min}^{-2}\right)$ represents the change in insulin action over time; $p_{2}$ represents rate of insulin action decline $\left(\mathrm{min}^{-1}\right) ; \mathrm{X}(\mathrm{t})$ stands for insulin action $\left(\mathrm{min}^{-1}\right)$, or the acceleration of glucose disposal associated with increased insulin concentrations; $\mathrm{p}_{3}$ represents the 
rate of insulin movement into the interstitial space $\left(\mathrm{min}^{-1}\right)$; $\mathrm{I}(\mathrm{t})$ stands for insulin concentration at time $\mathrm{t}(\mathrm{mIU} / \mathrm{L})$; and $\mathrm{Ib}$ represents baseline insulin concentration $(\mathrm{mIU} / \mathrm{L}){ }^{20,49}$ Assumptions for this model are $\mathrm{X}(0)=0$ and $[\mathrm{I}(\mathrm{t})-\mathrm{Ib}]=0$ if $\mathrm{I}(\mathrm{t})<\mathrm{Ib}{ }^{20}$

Acute insulin response to glucose $(\mathrm{AIRg}),\left(\mathrm{mU} \bullet \mathrm{min} \bullet \mathrm{L}^{-1}\right)$ enumerates endogenous insulin release in response to glucose presence, ${ }^{20}$ measured prior to exogenous insulin administration. ${ }^{49}$ Calculation of AIRg can be done using the following equation:

$$
\operatorname{AIRg}=\int[\mathrm{I}(\mathrm{t})-\mathrm{Ib}] \mathrm{xdt}
$$

where $\mathrm{I}(\mathrm{t})$ represents the insulin concentration at time $\mathrm{t}$, and $\mathrm{Ib}$ stands for basal insulin concentration. ${ }^{20}$ The above equation was integrated from $0<\mathrm{t}<10 \mathrm{~min}$ in compliance with the definition of AIRg proposed by Bergman. ${ }^{20,51}$

The disposition index (DI), a quantification of pancreatic $\beta$ cell responsiveness, is a measure of absolute insulin action potential attributable to initial insulin response and tissue sensitivity. ${ }^{49}$ The following equation can be used to calculate DI:

$$
\mathrm{DI}=\mathrm{AIRg} \times \mathrm{Si}
$$

Utilization of the minimal model allows for comprehensive analysis of the components affecting glucose disposal, insulin signaling, and the relationship between them. ${ }^{51}$ Practical applications for this method are often used in evaluation disease states, supplemental effects from drugs or nutraceuticals, and impacts of acute exercise or training. 


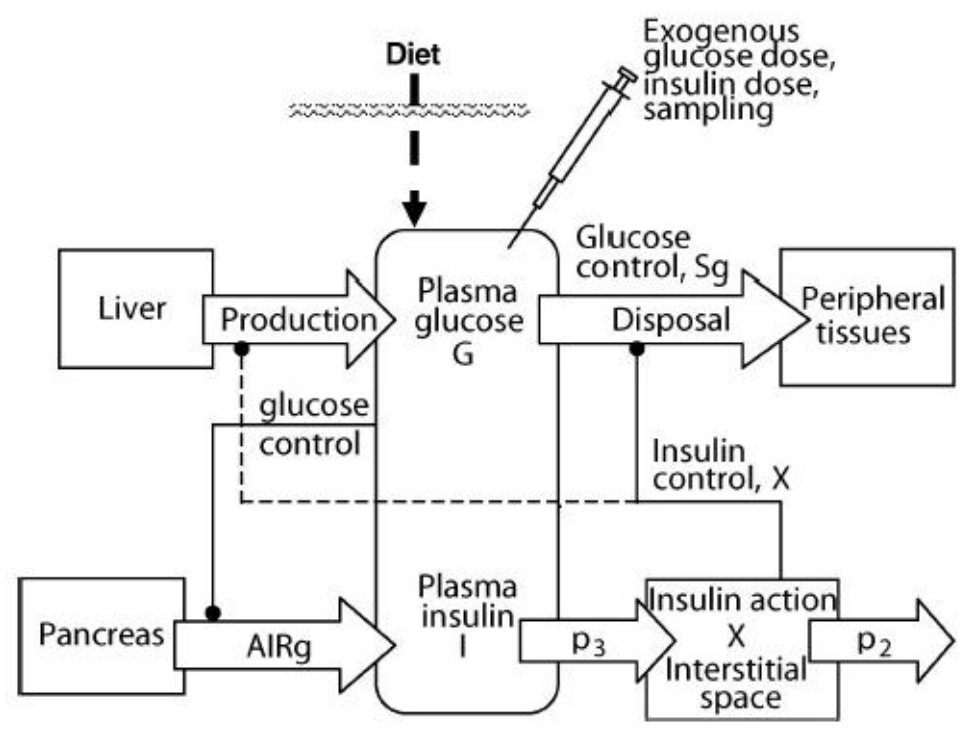

Figure 1: Diagram of the minimal model compartments. Variables correspond to equations and definitions within the text. ${ }^{20}$ 


\section{Factors Affecting Insulin Sensitivity}

Proper functioning of the physiological system can become compromised or enhanced due to numerous factors including, but not limited to, age, breed, nutrition, obesity, and exercise..$^{20,37,41}$ Further understanding of the impact these parameters have on glucose homeostasis within the horse can allow for manipulation of the system to elicit a desired response. Although disruption of normal function can be detrimental, knowledge of potential methods to alter glucose and insulin mechanics can have implications in disease prevention or treatment, exercise performance, and overall animal health.

Insulin sensitivity and glucose tolerance change over the course of a horse's life. During fetal development, foals in the second half of gestation have lower serum insulin concentrations than mature horses with similar levels of circulating glucose. ${ }^{20}$ Pancreatic $\beta$ cell response to glucose increases with fetal age ${ }^{52,53}$ prior to 230 days gestation exogenous glucose administration does not elicit an insulin release. ${ }^{53}$ Maturation of pancreatic $\beta$ cell function occurs over time, where insulin concentrations increase 24 to 48 hours post parturition, ${ }^{52,54}$ and increase to normal, mature levels at approximately 3 months after birth. ${ }^{55}$ Numerous studies across various models have shown that insulin sensitivity decreases with age, ${ }^{44,56-59}$ and the rate at which this decline occurs is dependent on environment, diet, genetics, and several other factors. ${ }^{60}$ Potential agerelated changes to insulin sensitivity may be due in part to factors affecting the hypothalamic pituitary adrenal axis, as changes in circulating levels of corticosteroids can impact insulin effectiveness over time. ${ }^{61}$ 
Differences in insulin sensitivity have also been noted across various equine breeds. Ponies are typically less insulin sensitive than horses, ${ }^{62}$ thereby having a slower glucose disposal rate. ${ }^{63,64}$ This characteristic makes pony breeds a good insulin insensitive model for evaluating the effects of long term hyperinsulinemia or hypyerglycemia on body systems and tissue function. ${ }^{41,64}$ Donkeys appear to have less sensitivity to insulin than ponies or horses; after an oral glucose tolerance test, donkeys and ponies have similar insulin concentrations, but donkeys had elevated glucose levels as long as $6 \mathrm{~h}$ post glucose administration. ${ }^{34}$ Draft breeds may have an improved insulin sensitivity over light breeds, as displayed by the increased rate of glucose infusion needed to maintain euglycemia for Belgian horses over Quarter horses during a clamp procedure ${ }^{65,66}$ More knowledge is needed to determine exact breed differences and consideration should be taken when making conclusions based on insulin or glucose measurements across breed types.

Dietary patterns play a key role in maintaining glucose homeostasis from many different angles. Chronic positive energy balance can contribute to obesity, and insulin resistance (IR), and despite the strong linkage between these two conditions, ${ }^{67}$ they can occur independently of one another. ${ }^{69}$ Management of nutrients in equine feedstuffs, including fat, protein, and starch can prevent the negative repercussions associated with overfeeding.

Insulin resistance (IR) is defined as the reduced cellular ability to respond to insulin and transport glucose from the bloodstream into the muscle and other tissues. ${ }^{22}$ In horses, IR is commonly associated with equine metabolic syndrome (EMS), ${ }^{20,41,69,70}$ pituitary pars intermedia dysfunction, or Equine Cushing's Disease, ${ }^{37,70}$ and some types 
of laminitis. ${ }^{41,71,72}$ Chronic hyperglycemia resulting from IR can cause toxic effects on the structure and function of many organs, including the pancreatic $\beta$ cells. ${ }^{21}$ Asplin and others demonstrated the ability to induce laminitis with prolonged infusion of insulin to achieve a hyperinsulinemic, hyperglycemic status, ${ }^{30,64}$ similar to the onset of laminitis observed with EMS. One potential mechanism for glucose toxicity can be explained via the formation of excess reactive oxygen species (ROS) which over time results in chronic oxidative stress, decreased insulin gene expression, and impaired insulin secretion. ${ }^{73}$ Damage or exhaustion of the pancreas has also been demonstrated in other models, ${ }^{22}$ with potential implications within equine metabolic syndrome. ${ }^{37}$

Concentrates are commonly fed to horses for many reasons. Ease of feeding provides appeal to horse owners, while increased energy composition of the feed can be applicable to the performance horse. Feeding concentrates as a supplement to forage increases energy and nutrient consumption for horses with needs above maintenance levels; however, overfeeding diets with high energy content can lead to obesity. In horses, high fat diets can be utilized to increase caloric load without inducing a high glycemic response ${ }^{67}$ and subsequent bouts of excitability. ${ }^{74}$ Enhancement of anaerobic ${ }^{75}$ and aerobic exercise performance ${ }^{76}$ has also been observed, however consideration must be taken into the amount and necessity of fat supplementation. As the most energy dense macronutrient $(9 \mathrm{kcal} / \mathrm{g})$, diets high in fat can cause weight gain and indirectly result in IR due to increased adiposity. ${ }^{74}$ Excess fat can be stored intramuscularly, and may play a role in reducing the tissue's sensitivity to insulin, ${ }^{67}$ along with excessive feeding of other nutrients. 
Excess protein within the diet is not only costly, but can negatively impact insulin sensitivity ${ }^{67}$ Several studies have shown that acute elevations in plasma amino acid concentrations decreases glucose disposal during a hyperglycemic euglycemic clamp trial, ${ }^{77-79}$ and excess leucine alone has minimized insulin mediated glucose uptake. ${ }^{80} \mathrm{~A}$ possible mechanism for decreased glucose transport displayed in response to excess amino acid presence may be due to the elevated inhibitory phosphorylation of IRS-1 achieved by mammalian target of rapamycin, or mTOR.$^{81}$ IRS- 1 inhibition thereby decreases PI3K, and negatively impacts the recruitment of GLUT4 through this pathway ${ }^{81}$ Also, due to the glucogenic or ketogenic abilities of amino acids, and therefore the ability for protein to contribute to energy storage, proteins should be fed at maintenance requirements. ${ }^{82}$

High intakes of non-structural carbohydrates have been associated with circulatory, hormonal, digestive, and metabolic changes, ${ }^{83}$ leading to the development of various disorders such as IR, metabolic syndrome, and laminitis ${ }^{84}$ Changes in postprandial glucose and insulin concentrations seen with diets high in starches and sugar are much greater than those associated with diets of forage alone or those supplemented with fat. $^{83,85,86}$

Prolonged levels of elevated glucose concentrations not only induce obesity, but also result in insulin insensitivity due to over-stimulation of the pancreas as well as tissue unresponsiveness due to hyperinsulinemia. This decrease in glucose clearance from the bloodstream causes conflicting signals to be sent through the tissues. On a circulatory level, the body responds to the increased levels of glucose by stimulating more insulin release; however, the tissues are not able to move glucose efficiently, and thus have to 
utilize other fuel sources. Often, this is manifested through fatigue or muscle wasting, due to the lack of glycogen stores within the muscle and utilization of protein for energy, respectively. Exercise along with dietary intervention can be implemented to counteract and prevent this condition.

\section{Effects of Exercise on Glucose Metabolism}

Physical exercise can be an important adjunct in mediating the glucose-insulin response in healthy, aged, and diseased animals. Similar to insulin, exercise increases the rate of glucose disposal into the contracting skeletal muscle cells by utilization of a different signaling pathway. A single bout of exercise has the ability to increase rates of glucose usage ${ }^{87,88}$ and increase insulin sensitivity at the muscle level, ${ }^{89}$ with effects lasting for hours after exercise has ended. ${ }^{90-92}$ Both short- and long-term exercise effects on glucose uptake and disposal have important roles in relationship to chronic metabolic control and acute regulation of glucose homeostasis. ${ }^{26}$

\section{Acute Exercise}

In the contracting muscle, the need for metabolic fuel is partially met though an increase in glucose uptake and utilization. Initially, this phenomenon was displayed in the masseter muscle; as chewing occurred, venous outflow showed decreased glucose concentration, suggesting a mechanism for glucose uptake during contractions. ${ }^{93}$ Over time, more information was collected to suggest potential methods for this increased disposal. Evidence has been found to suggest that in conjunction to increased glucose 
uptake during exercise ${ }^{94,95}$ acute exercise results in increased insulin sensitivity restricted to the exercised muscles.

The major mechanism by which glucose disposal is increased during exercise is through the recruitment of GLUT4. The exercise-induced translocation of this transporter is due to an increase in recruitment in association with the non-junctional transverse tubules upon contraction, rather than an increase in amount of GLUT4 protein present in the cell, or an increase in other GLUT isoforms. ${ }^{26,96-98}$ Although insulin concentrations during exercise are typically reduced, ${ }^{67}$ increased blood flow to the muscle during exercise may also increase the amount insulin presented to the muscle receptors, therefore causing the increased translocation of GLUT4. ${ }^{99}$ The effects of exercise and insulin can produce additive effects on GLUT4 movement, ${ }^{100-102}$ yet independent function is also displayed, suggesting the existence of different intracellular pools of the transporter that respond to each respective stimulus..$^{99,103,104}$

Post exercise increases in insulin sensitivity are typically characterized by elevated rates of basal and insulin mediated glucose uptake for several hours. ${ }^{101,105}$ Although the exact mechanisms in this response are unknown, replenishment of muscle glycogen stores, influence of endocrine mechanisms, and serum contents may elicit these effects. ${ }^{26}$ Degree of glycogen depletion can mediate the rate and duration of muscular glucose disposal after exercise due to the need to increase glycogen stores for the next bout of exercise. ${ }^{26}$ Insulin signaling is not altered by exercise as a single bout does not impact insulin receptor affinity, or tyrosine-kinase receptor signaling; ${ }^{106-108}$ however, increased presence of the hormone due to increased circulating levels of glucose from hepatic gluconeogenesis elicit the glucose disposal. Resulting hypoxia from exercise 
markedly amplifies glucose signaling in the muscles, by use of a signaling pathway which bypasses the insulin receptor, IRS-1, and the subsequent activation of PI3K in hypoxic conditions. ${ }^{109,110}$ Utilization of these mechanisms can be beneficial to the horse with hyperglycemia, as exercise can provide a transient decrease in blood glucose levels. Repetition of exercise bouts can elicit a larger, more prolonged response which can be instrumental in management of IR and long term improvement of glucose tolerance.

\section{Exercise Training}

The beneficial effects of exercise training may be due to the overlapping short term effects of each individual bout of exercise along with changes in gene transcription levels. Increased mRNA levels of insulin receptor, IRS-1, MAP kinase, ${ }^{111}$ and GLUT4

have been observed after exercise training in both healthy and insulin resistant models. ${ }^{112}$ Expression of the GLUT4 gene is also seen in trained athletes, in association with increased in insulin mediated glucose disposal. ${ }^{113,114}$ Comparison of an animal's response to an acute bout of exercise pre and post training can provide a comprehensive picture of the alterations seen to glucose metabolism. Implications for this type of program can be useful to determine if long term training effects can be influential in addressing symptoms associated with IR horses.

\section{The Exercising Equine Model}

Although evaluations of the effects of exercise on metabolic parameters are useful in determining the horse's ability to handle and recover from acute bouts of exercise, determination of overall body status changes in an exercising model are also important. Exercise can be performed at varying intensities, and monitored using numerous parameters including heart rate (HR), length of exercise, and time spent at each gait. ${ }^{82}$ 
Understanding the physical and metabolic demands of low, moderate, and high intensity exercise can be utilized to provide insight on the effects of supplementation.

Workload categories for horses have been established by evaluating the relationship between oxygen consumption and energy expenditure. Amount of energy utilized during exercise is dependent on the duration and intensity of the exercise bout. ${ }^{82}$ While duration is easy to quantify, intensity is often difficult to measure, as numerous factors can influence this parameter including ground resistance, incline, speed of movement. ${ }^{82}$ In regard to performance, degree of collection, height of jumps, and weight pulled or carried can greatly impact the workload performed by the horse,${ }^{82}$ and thereby alter the metabolic demands of the body.

Oxygen utilization and heart rate are closely correlated, therefore making it possible to determine approximate energy expenditure from heart rate. ${ }^{115}$ Due to this relationship, heart rate can be used to assess the workload performed by the horse, and is an integral tool utilized in the development of exercise programs. Heart rate during exercise is measured in order to properly evaluate the workload, as mean heart rate is used to determine exercise intensity. Light, moderate, heavy and very heavy exercise categories encompass varying athletic events, and tasks equine athletes are asked to perform, with mean heart rates for each bout at 80, 90, 110, and 110-150 bpm, respectively. ${ }^{83}$ Duration of exercise is also important to consider, as the amount of time spent at a given level of work can greatly alter energy expenditure and other factors including reactive oxygen species (ROS) generation, which can induce changes both locally and systemically. 


\section{Effects of Exercise on Oxidant Status}

Aerobic metabolism, the body's most efficient means of energy production, utilizes oxygen as the final electron acceptor in mitochondrial electron transport chain (ETC). Although most oxygen that enters the body is utilized in this manner, a small portion is susceptible to enzymatic alteration, direct chemical reactions, or modification by the cytochrome P450 superfamily, which utilizes oxygen for substrate oxidation., ${ }^{116}$ Combined with the oxygen that has not been fully reduced to water in the ETC, which amounts to approximately $1-2 \%$ of total oxygen intake, these compounds are referred to as reactive oxygen species (ROS). ${ }^{117}$ Accumulation of these compounds can be utilized for signaling or inflammatory responses within the body; however, prolonged elevated amounts can cause detrimental effects to lipid membranes, proteins, or nucleic acids. Oxidant status in the body is a constantly changing balance between reactive species and the defense systems utilized to keep their effects at bay. Conversion of ROS into effectively neutral compounds via the anti-oxidant defense system allows the body to cope with increased levels of ROS, and prevents against some of the damaging effects of these molecules on cells. ${ }^{1,16}$ Evaluation of this balance can provide insight to whole body oxidant status, as well as the degree of damage resulting from ROS.

\section{ROS Production}

Formation of ROS can occur in a multitude of different ways, including both radical and non-radical derivatives of oxygen. Molecular oxygen in the ground state is a bi-radical, containing two unpaired electrons in the valence shell, sharing the same spin. ${ }^{118}$ This similarity causes oxygen to react with one electron at a time. A free radical 
is an independent species with one or more unpaired electrons, formed by the loss or gain of a single electron. These molecules tend to be highly reactive, either accepting or donating electrons rapidly in order to achieve a more stable state of being. Reactive oxygen species is an inclusive term used to describe some free radicals, such as superoxide and hydroxyl, but also include some non-radicals such as hydrogen peroxide and hypochlorous acid. ${ }^{1}$ All radicals are ROS, however not all ROC are radicals, yet their reactivity allows them to easily strip electrons from other molecules, producing another free radical in the process. ${ }^{1}$ Generation of ROS can be seen throughout the cell, however the most important source of production is the ETC.

During normal metabolic function, the mitochondria utilize different states of respiration. Alterations in substrate availability and metabolic demands impact the changes between the different states of respiration. State 3 and 4 of respiration are commonly examined to further understand the impact of the ETC on cellular metabolism and oxygen utilization. ${ }^{1}$ State 3 represents the maximal oxygen consumption rate needed to meet metabolic ATP demands, whereas state 4 respiration is associated with maintenance ATP production costs. ${ }^{116}$ State 4 is also characterized by low ADP amounts, as the body is able to keep up with energy production; however, despite the lower flow of electrons through the chain, this state produces an abundance of superoxide radicals. This production occurs due to leakages caused by improper function of b-type cytochromes, like ubiquinone, which transports electrons from complex I and succinate to complex III, complex I constituents, and overall damage to mitochondrial organization. ${ }^{116}$ Other methods of ROS production include xanithine oxidase, electron leakage from nuclear or 
microsomal membranes containing cytochrome b5 and P-450, inflammatory response leading to increased activation of NADPX oxidase, ${ }^{1}$ along with many others.

\section{Functions of ROS}

Through the conversion of oxygen into water, various intermediates are formed, most of which contribute to the ROS pool. Most commonly superoxide, the hydroxyl radical, and hydrogen peroxide are measured due to their prevalence within this conversion and their role within the body. Despite the negative connotation associated with ROS, a certain level of intracellular production is necessary to activate growth, differentiation, proliferation and apoptotic programming. ${ }^{119}$ Superoxide, a highly reactive molecule, is often formed first from leaky channels within the ETC, which can then be dismutated spontaneously or by superoxide dismutase (SOD) into hydrogen peroxide. ${ }^{120}$ Hydrogen peroxide is a non-radical and a weak oxidant, with a long half-life, permitting diffusion across cell membranes, and interaction with many different cellular molecules allowing for the activation of a variety of signaling pathways. ${ }^{2}$ Redox regulation, such as the nuclear factor kappa-light-chain-enhancer of activated B cells (NF-kB) transcriptional activators, rely on signaling from ROS to relieve inhibition from IkB proteins, thereby allowing for transcription of several antioxidant enzymes including copper-zinc and manganese SOD. ${ }^{119}$ Mitochondrial biogenesis and metabolic changes seen in response to exercise may be coordinated through ROS signaling of transcription factors and

coactivators. ${ }^{119}$ Although the exact role of ROS in many signaling pathways is unknown, measurement of ROS activity and presence is critical to understanding the function of these molecules. 


\section{Detection Methods}

Measurement of ROS can be challenging, due to their highly reactive nature and relatively short time of existence. Direct and indirect detection and fingerprinting can be used to determine the presence of ROS, measure the concentration of specific ROS species, and assess damage caused to cellular molecules. Direct measurements can be made through electromagnetic spin resonance used to detect the presence of an unpaired electron using a magnetic field. This method can also be utilized to detect changes in transition metal ions used in ROS production. ${ }^{121}$ Although this method can be used in vivo, it has low sensitivity, therefore making it difficult to detect highly reactive radicals. Spin trapping is often used to overcome this, as it is highly sensitive. Reactive oxygen species are allowed to react with selected molecules to produce a more stable compound that can be detected and measured reliably. ${ }^{122}$ When used in combination with one another, these methods can provide a big picture view of ROS within an in vivo model. Indirect methods of detection are used to quantify their concentrations, with various methods applied dependent on the ROS to be evaluated. Superoxide detection methods include reductions of nitroblue tertazolium or cytochrome c, and oxidation of lucigenin. ${ }^{121}$ Unfortunately, reduction methods display low specificity and sensitivity, as many compounds besides superoxide can reduce these molecules while lucigenin oxidation is subject to artifact production, and care should be taken when analyzing results from these methods. ${ }^{121}$ Hydrogen peroxide can be measured reliably using horseradish peroxidase assays utilizing a specific reaction to produce a fluorescent product for detection. Also, probes for tissue detection of ROS can be used; however, caution should be taken to ensure accumulation of the probe does not occur in a particular 
cell compartment. ${ }^{122}$ Concentration of the hydroxyl radical is most commonly determined using the tryptophan reaction or utilizing the conversion of DMSO to methane gas and calculating the rate of change relative to radical presence. Hydroxyl radicals are detected using the tryptophan method by measuring the formation of 5-hydroxytryptophan luminescence induced by multiphoton excitation. ${ }^{123}$

Fingerprinting is an effective means utilized to determine the reactions of ROS with cellular components due to their characteristic end products. Proteins, lipids, and nucleic acids are the main targets for ROS damage. Damage to proteins is primarily quantified via amino acids with reactive carbonyl groups as they are the most easily measured experimentally. ${ }^{122}$ Measurement is determined by the interaction of oxidized protein molecules with dinitrophenylhydrazine, utilizing a fluorescent or radiochemical method of analysis. Although this method is reliable, the tissues are susceptible to proteolysis and other altering reactions that may skew results. ${ }^{122}$ Lipid peroxidation is the most widely measured form of ROS fingerprinting, as many of the assays are easy to use and provide good results. Loss of unsaturated fatty acids can be measured through high performance liquid chromatography, while peroxide assays can be conducted for glutathione peroxidase, cyclooxygenase, and many more. ${ }^{122}$ End-product measurements are also used to gain a broader view of overall lipid peroxidation, such as thiobarbituric acid reactive substances assays. Nucleic acid damage can be quantified using purine and pyrimidine base modification via the detection of 8-hydroxydeoxyguanosine, formed in the presence of a hydroxyl radical. ${ }^{122}$ Strand breakage can also be quantified, as oxidation of the strands will cause cleavage, resulting in detectable fragments. Deoxyribose 
oxidation is not easy to measure, and should not be used as a sole indicator of damage, since multiple products are produced.

Although ROS production is necessary within the body for proper signaling and other homeostatic functions, excessive production can elicit damaging responses. ${ }^{1}$ Potential mediation beyond naturally occurring defense mechanisms in the body can be employed to buffer or prevent these changes. From an exercise perspective, reduction in excessive ROS production and damage could result in increased performance due to decreased insult to cellular components. ${ }^{119}$ Phytochemicals, compounds which naturally occur in plants, may have an impact on overall health and are commonly fed to horses as a supplement in hopes of preventing ROS damage. ${ }^{4}$ Although some of these compounds are used extensively, knowledge of their function, efficacy, and safety are limited, and require further research.

\section{$\underline{\text { Resveratrol }}$}

Naturally, plants synthesize a wide array of compounds which have potential health benefits when eaten. Resveratrol (trans-3, 4', 5-trihydroxystilbene, figure 2), a phytocompound found most commonly in grapes, red wine, yucca, and peanuts, ${ }^{4-6}$ has been found to act as a powerful antioxidant and anti-inflammatory agent, along with having beneficial effects against ageing and metabolic diseases. ${ }^{6}$ Administration of resveratrol has been shown to cause a reduced amount of edema, ${ }^{123}$ increased muscle strength and endurance, ${ }^{8,124-127}$ along with protecting skeletal muscle from the deleterious effects of oxidative stress through alterations in metabolism ${ }^{8,123,125-127}$ and reduced 
protein catabolism. ${ }^{8,124-127}$ Additionally, within skeletal muscle, resveratrol has been found to increase insulin stimulated glucose $\operatorname{transport}^{9}$ and improve glucose homeostasis. ${ }^{8}$ By limiting the detrimental effects on metabolism combined with reductions in tissue injury, increased exercise performance may then be expected to occur in response to resveratrol supplementation in horses.

\section{Synthesis and Structure}

Resveratrol is a phytoalexin, meaning synthesis of the compound can be induced by microbial infections, ultraviolet radiation and exposure to ozone. ${ }^{128}$ Grapes are the primary source of naturally occurring resveratrol, ${ }^{129}$ with concentrations of the compound is found in the leaf epidermis and the skin of grape berries, but not within the flesh. ${ }^{128-130}$ Stilbene synthase, the terminal enzyme in the production pathway is activated in response to exogenous stress factors, ultra-violet radiation and chemical signals from pathogenic fungi. ${ }^{130}$ Levels of resveratrol peak approximately $24 \mathrm{~h}$ post stress exposure, and decline $48-72 \mathrm{~h}$ later due to the activation of catabolic stilbene enzymes. ${ }^{130}$ Concentration of resveratrol in grapes is dependent upon maturity and variety of the grape, along with duration of stress exposure.Grape leaves reach concentrations ranging $50-400 \mu \mathrm{g} / \mathrm{g}$ fresh weight, while fresh grape skin content ranges $50-100 \mu \mathrm{g} / \mathrm{g} .{ }^{128}$ Resveratrol can occur in multiple forms, both of which are counted in these concentrations.

Resveratrol exists in two isoforms, trans- and cis-, each having their own properties and functions. Although the cis conformation may possess numerous health benefits, it is not widely studied at this time. ${ }^{131}$ Plants can also synthesize stillbenoid glucosides, forming cis- and trans- resveratrol 3-O $\beta$ glucoside, ${ }^{129}$ which when cleaved 
can produce a free glucose molecule. Resveratrol can also be obtained through organic synthesis; trans-resveratrol is most often formed first, and when exposed to ultra violet irradiation changes into the cis conformation. ${ }^{130}$ Research on the biological properties of resveratrol such as bioavailability and function were limited until the compound could be synthesized, as pure extraction from the grape skin and leaves is difficult to achieve.

\section{Bioavailability and Metabolism}

Bioavailability of a nutrient is defined by the amount available to the target tissue after administration, including absorption, distribution, and metabolism of the compound. Resveratrol absorption from the intestine is rapid, ${ }^{132-135}$ allowing for distribution to various organs, primarily the liver, kidneys, brain, lungs, and muscle. ${ }^{135,136}$ Absorption of resveratrol is not greatly impacted by the vehicle in which it is administered. In humans, resveratrol is most commonly consumed in red wine, but can also be found in grape juice and vegetable homogenates. ${ }^{137}$ Although resveratrol content can vary depending on previously mentioned variables, a previous study held resveratrol concentration constant among different matrices to determine absorption rate. ${ }^{137}$ The matrix used to deliver the compound does impact total resveratrol when administered utilizing the different forms of adminsitration. ${ }^{137}$ In order to travel through the body, resveratrol must be bound to protein or become conjugated, primarily into resveratrol-3-glucoronide or resveratrol-3sulfate, to remain at elevated concentrations in the serum due to its low water solubility. ${ }^{138}$ Albumin is thought to be one of the main plasma protein transporters of unconjugated resveratrol due to its physical properties allowing it to bind to hydrophobic compounds. ${ }^{139,140}$ The compound is also shown to interact with lipoproteins in a lipid concentration dependent manner. ${ }^{141}$ The efficiency of any compound is greatly related to 


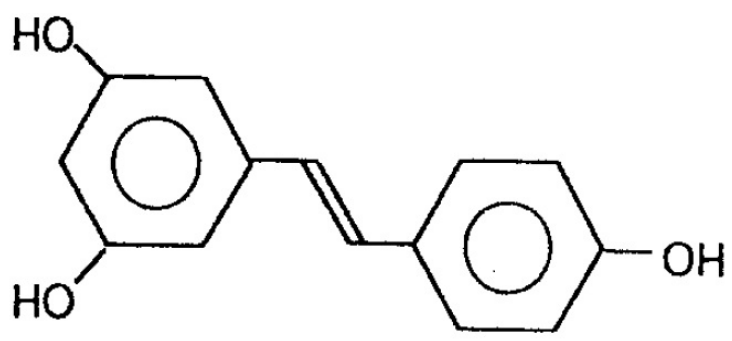

Figure 2: Trans-resveratrol (trans-3, 4', 5-trihydroxystilbene). ${ }^{129}$ 
its selectivity and affinity to protein transporters, which can aid in tissue recognition of the molecule.

Upon absorption, delivery of protein bound or conjugated resveratrol to the tissues occurs, with the liver having the highest accumulation of the compound. ${ }^{128,136}$ Uptake of resveratrol into the liver occurs via passive diffusion, and carrier mediated transport. Utilization of radiolabeled resveratrol allowed for the examination of time, dose, and temperature dependencies of resveratrol uptake into the organ, finding that carrier facilitated transport is primarily used to allow for efficient and specific uptake of resveratrol. ${ }^{142}$ The liver seems to be a reservoir of resveratrol and its conjugated metabolites, resulting from metabolism both in the intestine and the liver. The function of this pool is not entirely understood; however, it is thought to be partially responsible for the prolonged effects of resveratrol after a bolus dose. Detectable levels of resveratrol can occur as early as 15 min post resveratrol administration, with peak concentrations occurring 30 min after dosage. ${ }^{136}$ Although free resveratrol content begins to decline $1 \mathrm{~h}$ post-dosage, ${ }^{143}$ resveratrol metabolites remain in the circulation for longer periods of time. A second resveratrol peak occurs approximately $6 \mathrm{~h}$ post administration, due to enteric recirculation of conjugated metabolites. The presence of these metabolites is known to aid in the elevation of detectable levels of resveratrol in the blood over time, ${ }^{128,}$ 136, 144 which may contribute to the efficacy of resveratrol within the body; however, the exact function of these structures remains to be determined. It is important to note the effects of resveratrol and the time course during which the free and conjugated forms can be detected may be dose dependent, which will be later discussed in detail. 
Removal of resveratrol from the body is accomplished mainly through renal excretion. Decreasing concentration of radiolabelled resveratrol metabolites in the kidneys strongly suggests their primary role in elimination of these compounds from the body. ${ }^{133,134}$ Some elimination may occur through biliary binding pathways, although minimal research has been conducted in this area. ${ }^{128}$ Resveratrol-3-sulfate and resveratrol-3-glucoronide are found in the urine of rodents and humans; ${ }^{135,143}$ however, species variation should be taken into consideration, along with differences due to dose rate and concentration. Free resveratrol has not been found in murine or human urine, ${ }^{143}$ suggesting that the majority of free resveratrol is either utilized by the peripheral tissues or conjugated and stored by the liver or excreted.

\section{Functions}

Resveratrol is currently known for its antioxidant, anti-inflammatory, anti-cancer and chemopreventative abilities. Interest in resveratrol began when an inverse correlation was found between red wine consumption and cardiovascular disease occurrence. ${ }^{129}$ The compound was first thought to be the biologically active ingredient in red wine in $1992,{ }^{145}$ causing extensive research into the effects of resveratrol within the body. Currently, resveratrol is known to impact numerous mechanisms and pathways within the body, including inhibition of lipid peroxidation, free-radical scavenging, alteration of eicosanoid synthesis, modulation of lipid metabolism, improvement of insulin sensitivity, anti-inflammatory activity and estrogenic activity. ${ }^{9,128-131}$ For the purpose of this review, lipid peroxidation, modulation of lipid metabolism and improvement to insulin sensitivity will be the primary focus. 
Resveratrol prevents the peroxidation of membrane lipids by ROS. ${ }^{129,146,147}$ Resveratrol acts as a scavenger of free radicals, preventing the oxidation of membrane lipids. ${ }^{146}$ Maintenance of structural integrity of the plasma membrane is crucial to proper cellular function, and can have detrimental effects on exercise performance. Preventative effects are not limited to the muscle cells; it has been shown that resveratrol has prevented damage due to peroxidative stress in dopaminergic neuronal and hepatic cells. ${ }^{146,147}$ The compound has also been found to prevent metal induced lipid peroxidation within microsomes and low-density lipoproteins (LDL). ${ }^{148}$ Alterations in the conformation of LDLs can increase the amount of circulating fatty acids in the bloodstream, due to structural changes in apo $\mathrm{B}$, thereby affecting catabolism by the $\mathrm{B} / \mathrm{E}$ receptor system, ${ }^{121}$ aiding in the predisposition of the animal to numerous metabolic diseases.

Modulation of lipid metabolism can also occur due to resveratrol supplementation. Resveratrol has been shown to increase silent information regulator 2 homolog (SIRT) 1 and peroxisome proliferator -activated receptor (PPAR)- $\gamma$ coactivator1 (PGC1) in muscle, ${ }^{123}$ resulting in an altered metabolism displaying an increased sensitivity to insulin, along with a preferential switch to fat as a fuel source. ${ }^{149}$ Increases in fatty acid transporter content, PPAR- $\gamma$ pathway activation, and fat oxidation enzymes are responsible for this shift. The glucose sparing effect of resveratrol allows for more glucose to be stored as glycogen, and a decrease in fat available for deposition in the adipocytes. Reduction in circulating fatty acids in the blood stream combined with improved insulin sensitivity makes resveratrol a potential mediator for type 2 diabetes in humans, and a potential area of interest for equine metabolic syndrome. 
Resveratrol has been shown to improve insulin resistance via enhancement of enzyme activity involved in glucose metabolism, along with increasing the insulin sensitive cell's ability to respond to the hormone. In a streptozotocin-nicotinamideinduced diabetic rats, resveratrol supplemented orally at $5 \mathrm{mg} / \mathrm{kg} \mathrm{BW}$ for 30 days was able to alter activities of key carbohydrate metabolism enzymes such as hexokinase and pyruvate kinase, which returned back to normal concentrations, allowing for normal flux of the substrate through this catabolic pathway. ${ }^{150}$ Reduction of circulating glucose is achieved by enhancement of GLUT-4 translocation, perhaps due to resveratrol's actions on PGC-1. ${ }^{151,152}$ In mice, resveratrol supplementation at $400 \mathrm{mg} / \mathrm{kg} \mathrm{BW}$ daily increased levels of PGC-1 $\alpha$ acetylation, leading not only to an increase in glucose transport, but also to an induction of oxidative phosphorylation genes and mitochondrial biogenesis. ${ }^{152}$ Increasing the cells ability for glucose uptake and metabolism can aid to alleviate hyperglycemia along with ensuring substrate availability in the cell for utilization and storage.

Increased circulating levels of ROS, excessive circulating free fatty acid levels, and hyperinsulinemia, can all cause oxidative stress, resulting in chronic inflammation, insulin resistance, and decreased exercise performance. ${ }^{29}$ Resveratrol acts to diminish oxidative stress via induction of mitochondrial MnSOD expression and activity. ${ }^{153} \mathrm{~A}$ potential mechanism of action for this result begins with resveratrol increasing the SIRT 1 to $\mathrm{NAD}+$ ratio, leading to an increase in FOXO3, resulting in increased MnSOD activity. Other enzymes, such as $\mathrm{CuZn} \mathrm{SOD,} \mathrm{glutathione} \mathrm{peroxidase,} \mathrm{and} \mathrm{catalase} \mathrm{display}$ either remain the same or decrease in activity the presence of resveratrol supplementation. $^{153}$ 


\section{Dosage}

Despite the extensive research conducted across murine and human models, an effective dose for resveratrol has yet to be established. Administration rates, concentrations, and durations are widely varied, making it difficult to determine appropriate means through which beneficial effects can be seen. Fresh grape skin contains $50-100 \mathrm{mg}$ resveratrol/g, ${ }^{154}$ making the content of naturally occurring beverages containing the skin vary greatly as well. In red wine, the range of detectable transresveratrol spans from non-detectable levels to $14.3 \mathrm{mg} / \mathrm{L}(62.7 \mu \mathrm{M})$, with reported health benefits seen at average levels, $1.9 \pm 1.7 \mathrm{mg} / \mathrm{L}(8.2 \pm 7.5 \mu \mathrm{M}) .{ }^{130}$ During early resveratrol trials, wine of a known content was used as the main method of dosage. Even then, duration and concentration of supplementation varied greatly; $86 \mu \mathrm{g}$ resveratrol $/ \mathrm{kg} \mathrm{BW}$ for a single dose, or $43 \mu \mathrm{g}$ resveratrol $/ \mathrm{kg} \mathrm{BW}$ once daily for 15 days. ${ }^{132-134}$ The trend continues through much of the literature utilizing a more "natural" form of resveratrol, and has transcended through present day.

The development of organic synthesis of trans-resveratrol opened the door to further research on the compound without concern of competition or conflicting results due to competition of other flavinols present in wine. Despite this advancement, resveratrol could then be administered in greater doses, over greater time periods, along with the option of injectable administration. Intragastric administration to mice has been supplemented from values ranging to $0.228 / \mathrm{kg} \mathrm{BW}$ to $60 \mathrm{mg} / \mathrm{kg} \mathrm{BW}$, making it difficult to elucidate the appropriate dose on a weight basis. ${ }^{133,135,149}$ In human studies, supplementation levels have been reported at $0.03 \mathrm{mg} / \mathrm{kg} \mathrm{BW}$ to $0.35 \mathrm{mg} / \mathrm{kg} \mathrm{BW}$, with many other values in-between. ${ }^{137}$ Duration of supplementation also varies tremendously; 
some literature touts the benefits of a loading dose of high concentration, followed by a lower maintenance dose, while others remain at a specified concentration over time. Single dose administration seems to be utilized only during trials for which absorption, metabolism, or clearance are the primary areas of evaluation.

Resveratrol in the Equine Industry

Regardless of level, resveratrol supplementation appears promising. Many nutritional supplements fed to performance horses today contain resveratrol. Lack of regulation in this area of equine nutrition allows for extreme flexibility in the content of each supplement and the claims made in regards to their suggested benefits to the horse. Many companies have begun to incorporate resveratrol into their products at varying concentrations, usually in conjunction with other compounds with suggested health benefits. Utilization of this compound in the athletic horse can lead to a decrease in ROS damage, therefore decreasing the detrimental effects seen with prolonged exercise at varying intensities.

Along with its popularity within the equine performance horse industry, resveratrol also has a potential role for the metabolic syndrome animal. Maintenance of these animals is often difficult, with the primary goal of treatment to reduce BW and return insulin sensitivity and glucose tolerance to a normal level to prevent laminitis and worsening of the condition. Due to the positive benefits in other models, resveratrol supplementation may be beneficial to the treatment of this condition by increasing glucose transport, shifting to fat as the preferred metabolic fuel source, and increasing oxidative capacity through mitochondrial biogenesis. ${ }^{152}$ 
Despite the current popularity and the vast potential uses for resveratrol within the equine industry, no published research is currently available within an equine model. Without this data, speculation and testimonials from consumers are used to evaluate the function of resveratrol within the horse and market the compound to the equine industry. Evaluation of both an athletic and EMS model are needed to fully elucidate the effects of resveratrol within the horse. A better understanding of how resveratrol contributes to equine health and potential performance could be obtained by evaluating various parameters relating to glycemic response, levels of oxidative damage, and inflammation, with consideration given to the findings of previous studies in other models. 


\section{STATEMENT OF PROBLEM, OBJECTIVE, AND HYPOTHESIS}

In both human and rodent models, research has been conducted to determine the effects of resveratrol. Diets high in this phytocompound are synonymous with good health, with applications in various models and disease states. Specifically, resveratrol has been found to have both antioxidant and anti-inflammatory properties, while at the same time improving cellular glucose dynamics. While numerous equine performance supplements contain resveratrol, no research has been conducted utilizing an equine model.

Therefore, the objectives of the proposed study are to utilize a mature, athletic horse model to (1) examine the ability of resveratrol to act as an antioxidant molecule to protect the body against oxidative damage and lipid peroxidation, (2) determine the effect of resveratrol supplementation on basal plasma insulin and glucose concentrations, as well as glucose and insulin dynamics during a frequently sampled glucose tolerance test.

The hypotheses of this study were that resveratrol supplementation would (1) improve oxidant status within the moderately exercised equine model by reducing the level of lipid peroxidation within the body (as measured by TBARS), and (2) increase insulin sensitivity and glucose tolerance as displayed by the Minimal Model parameters. 


\section{CHAPTER II: MATERIALS AND METHODS}

The West Virginia University Animal Care and Use Committee approved all methods and procedures used in these experiments.

\section{Animals and Diet}

Six, healthy, fit, mature Quarter Horse geldings (equus caballus) were used in this study $(10 \pm 1 \mathrm{yr})$. The Quarter Horse breed was used due to its popularity within the United States, versatility among various performance events, and industry impact due to the large population within the targeted marketing group. Prior to use for this project, all horses were used for the Equestrian Technology course offered by West Virginia University, where they were exercised lightly 3 to 4 times per week for approximately 1 hour per week, mainly at the walk and trot, by riders of all experience levels. All horses began the study with a body condition score (BCS) of $5.5 \pm 0.5$, which was maintained through the duration of the trial. Body weights (BW) were taken on day 0 , and 10 , and 14 of each treatment period and are further described later.

Horses were brought in one week prior to the start of the study to allow for dietary adjustment from pasture. Geldings were housed in $3.05 \times 3.05 \mathrm{~m}$ box stalls at West Virginia University Reedsville Experiment Farm, with turnout in pairs $1 \mathrm{~h}$ per day in a sand arena, to ensure dietary control through the course of the study. Horses were offered a commercially available concentrate ration (Southern States Legends Show and Pleasure Pellets, Richmond, VA) at $0.5 \%$ BW and grass hay (West Virginia University Agronomy Farm, Morgantown, WV) at $1.75 \%$ BW divided into two feedings daily. The ration was formulated to meet National Research Council ${ }^{82}$ recommendations for mature 
horses in moderate work. Hay and concentrate samples were analyzed by a commercial laboratory (Equianalytical laboratories, Ithaca, NY). A summary of feed analyses can be found in Table 1. On an as-fed basis, concentrate provided $2.75 \mathrm{Mcal} / \mathrm{kg}$ and hay provided $1.97 \mathrm{Mcal} / \mathrm{kg}$. All feedstuffs were weighed prior to feeding, and any refusals were recorded to determine actual daily intake. Horses were provided ad libitum access to water. Geldings were accustomed to the barn, and general laboratory procedures.

\section{Resveratrol Supplementation}

Horses were assigned to treatment groups using a Latin Square crossover design (Figure 3). Treatment groups included control (C, no supplementation), low supplementation (L) of $2.5 \mathrm{~g}$ trans-resveratrol once daily, and high supplementation $(\mathrm{H})$ of $5 \mathrm{~g}$ trans-resveratrol once daily.

Resveratrol is generally regarded as safe (GRAS). The supplement was compounded (Equithrive, Lawless, KY) with a concentration of $1 \mathrm{~g}$ of $99 \%$ pure micronized resveratrol per $10 \mathrm{~g}$ polyethylene glycol-based paste, therefore horses received a total of $25 \mathrm{~g}$ or $50 \mathrm{~g}$ of product in the $\mathrm{L}$ and $\mathrm{H}$ dosage groups, respectively. The resveratrol micronization process ensures that $90 \%$ of particles measure less than $10 \mu \mathrm{m}$, and when combined with polyethylene glycol, makes the compound more water-soluble and thus should increase bioavailable. These levels of supplementation reflect values currently used in rodent and human research, calculated on a basis for a $500 \mathrm{~kg}$ average horse to receive $5 \mathrm{mg} / \mathrm{kg}$ and $10 \mathrm{mg} / \mathrm{kg}$. Metabolic BW (MBW, defined as $\mathrm{BW}^{(0.75)}$ ) was calculated ${ }^{82}$ to ensure supplementation levels were adequate in relationship to metabolism of the compound for species used in previous research. Average BW for each species was determined as; rat: $230 \mathrm{~g},{ }^{155}$ mouse: $20 \mathrm{~g},{ }^{155}$ human: $70 \mathrm{~kg},{ }^{156}$ horse: $500 \mathrm{~kg} .{ }^{82}$ When compared on a MBW 
Table 1: Nutrient analysis (DM basis, Equi-analytical, Ithaca, NY) for hay and concentrate, fed at levels in accordance with NRC recommendations, to mature Quarter Horse geldings performing moderate intensity exercise to for a total of 9 weeks; 1 week acclimation prior to study, 3 periods of 2 week supplementation, and 1 week washout periods in between treatments.

\begin{tabular}{ccc}
\hline Nutrient Content (Dry Matter Basis) & Concentrate & Hay \\
\hline Digestable Energy (DE, Mcal/kg) & 3.1 & 2.2 \\
Crude Protein $(\mathrm{CP}, \mathrm{g} / \mathrm{kg})$ & 146.4 & 143.6 \\
Acid Detergent Fiber (ADF, g/kg) & 152.7 & 354.0 \\
Neutral Detergent Fiber (NDF, g/kg) & 315.8 & 562.4 \\
Water Soluble Carbohydrates (WSC, g/kg) & 95.5 & 101.2 \\
ESC (Simple Sugars, $\mathrm{g} / \mathrm{kg})$ & 40.1 & 85.1 \\
Crude Fat $(\mathrm{g} / \mathrm{kg}, \%)$ & 67.3 & 31.6 \\
Calcium $(\mathrm{g} / \mathrm{kg}, \%)$ & 7.9 & 9.7 \\
Phosphorus $(\mathrm{g} / \mathrm{kg}, \%)$ & 6.0 & 2.2 \\
\hline
\end{tabular}


basis, dosages utilized for this study are applicable to those commonly seen in literature for other models.

Supplementation was conducted over $14 \mathrm{~d}$, with a $7 \mathrm{~d}$ washout period in between each treatment. During the treatment period, horses were moderately exercised three times per wk as per the protocol detailed below.

\section{Exercise Protocol}

In order to assess the effect of resveratrol on an exercising conditioned model, horses maintained a moderate level of activity through the study. Turnout was allowed for $\sim 2 \mathrm{~h}$ per day during treatment and washout periods. Horses were exercised 3 times per week for $60 \mathrm{~min}$, with at least one day of rest in between exercise bouts. In accordance with the NRC, moderate intensity exercise is defined as 3-5 h per week, with a mean heart rate of 90 beats/min, during which $30 \%$ of exercise time should be spent at the walk, $55 \%$ at the trot, and $10 \%$ at the canter. ${ }^{82}$ Using these guidelines, the following exercise protocol described in Table 2 was followed for the duration of the study, with a total time at the walk, trot and canter being 18, 30, and 12 min, respectively.

An equine heart rate monitor (Polar Equine, Lake Success, NY) was utilized to monitor heart rate during exercise bouts. Heart rate was monitored starting approximately $10 \mathrm{~min}$ prior to exercise to allow acclimatization of the system, and to ensure the horse was at rest before starting to work, and continued through the entire exercise set. Gait speed was adjusted to maintain heart rate within the target range. All horses were ridden by a set of riders with similar skill sets, and all exercise bouts were overseen by one individual to ensure continuity through the study. All horses remained sound through the course of the project. 


\begin{tabular}{|c|c|c|c|c|}
\hline & \multicolumn{3}{|c|}{ Treatment } \\
\hline & & $\mathrm{C}$ & $\mathrm{L}$ & $\mathrm{H}$ \\
\hline \multirow{3}{*}{ 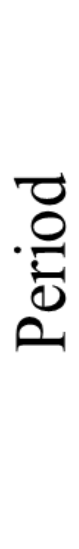 } & 1 & $\begin{array}{c}\text { Horse } \\
\text { A, B }\end{array}$ & $\begin{array}{c}\text { Horse } \\
\text { C, D }\end{array}$ & $\begin{array}{c}\text { Horse } \\
\text { E, F }\end{array}$ \\
\hline & 2 & $\begin{array}{c}\text { Horse } \\
\text { C, E }\end{array}$ & $\begin{array}{c}\text { Horse } \\
\text { A, F }\end{array}$ & $\begin{array}{c}\text { Horse } \\
\text { B, D }\end{array}$ \\
\hline & 3 & $\begin{array}{c}\text { Horse } \\
D, F\end{array}$ & $\begin{array}{c}\text { Horse } \\
\text { B, E }\end{array}$ & $\begin{array}{c}\text { Horse } \\
\text { A, C }\end{array}$ \\
\hline
\end{tabular}

Figure 3: Latin square crossover design used to rotate control (C, no supplementation), low resveratrol supplementation (L), and high resveratrol supplementation $(\mathrm{H})$ between 6 mature Quarter Horse geldings during 3 treatment periods of 2 weeks each. Between each treatment period a 1 week washout period was allowed to pass before the next treatment was administered. 
Table 2: Exercise protocol designed to mimic moderate intensity exercise in accordance with NRC guidelines.

\begin{tabular}{ccc}
\hline Time (min) & Target HR (range) & Expected Gait \\
\hline $0-6$ & $60(40-80)$ & Walk \\
$6-12$ & $90(70-110)$ & Trot \\
$12-15$ & $110(90-130)$ & Canter \\
$15-18$ & $90(70-110)$ & Trot \\
$18-21$ & $110(90-130)$ & Canter \\
$21-27$ & $90(70-110)$ & Trot \\
$27-33$ & $70(50-90)$ & Walk \\
$33-39$ & $90(70-110)$ & Trot \\
$39-42$ & $110(90-130)$ & Canter \\
$42-45$ & $90(70-110)$ & Trot \\
$45-48$ & $110(90-130)$ & Canter \\
$48-54$ & $90(70-110)$ & Trot \\
$54-60$ & $70(50-90)$ & Walk \\
\hline
\end{tabular}




\section{Blood Samples and Muscle Biopsies}

Blood samples were collected into sodium heparin tubes (Vacutainer, Franklin Lakes, NJ) on d 0 and 14 of supplementation within $24 \mathrm{~h}$ of an exercise bout for later analysis of TBARS concentration. Samples were pulled, placed immediately on ice, and transported to the West Virginia University Main Campus for further processing. Samples were centrifuged at $3000 \mathrm{xg}$ for $1 \mathrm{mi} \mathrm{n}$, and stored at $-2 \mathrm{C}$ until analysis. Muscle tissue biopsies were collected on day 0 and 14 of each treatment period. A Bergstrom biopsy needle was used to collect tissue samples from the middle gluteal

muscle. ${ }^{157}$ All geldings received Xylazine $(0.5 \mathrm{mg} / \mathrm{kg})$ sedation and were given Lidocaine anesthesia (8-10cc of $20 \mathrm{mg} / 50 \mathrm{~mL}$ concentration) at the biopsy site $\sim 10$ minutes prior to sampling. Samples were dissected into $0.25 \mathrm{~cm}$ pieces, immediately flash frozen in liquid nitrogen, then stored at $-80 \mathrm{C}$ until later analysis for resveratrol concentration (results not shown).

Frequently Sampled Intravenous Glucose Tolerance Test (FSIGT)

All horses were subjected to a FSIGT on d 10 of resveratrol supplementation during each treatment period. Concentrate and hay feedings were withheld for the duration of the test, and at least $12 \mathrm{~h}$ had passed since the last feeding. The protocol for this test was determined from previously published methods, described below. ${ }^{20}$

Geldings were weighed using an electronic scale and catheterized (Abbocath, 14g, 5.5 in, Abbott Laboratories, Abbott Park, IL) using aseptic technique and Lidocaine anesthesia between 0730 and 0830 . Horses were paired randomly to allow for test staggering. Baseline blood samples $(\sim 25 \mathrm{ml})$ were collected 30 minutes prior to the start of each test, at approximately 0900, 0930 and 1000, respectively. A glucose bolus of 
0.3g/kg BW (dextrose solution, 50\%, Phoenix Pharmaceutical, Inc, St. Joeseph, MO) was infused via catheter over a 2 min period. Twenty min after the glucose dose, an insulin bolus (Humulin R, Williow Birch Pharmaceutical, Inc, Taylor, MS) of 30mIU/ kg of BW was administered via catheter. The primary function of the insulin bolus was to administer a physiological, not pharmacological, dose of insulin, to prevent prolonged hyperglycemia, and prevent hypoglycemia. ${ }^{20}$

The test was conducted over $\sim 3 \mathrm{~h}$, during which blood samples $(\sim 25 \mathrm{ml})$ were collected at -30, 0, 1, 2, 3, 4, 5, 6, 7, 8, 10, 12, 14, 16, 19, 22, 23, 24, 25, 27, 30, 35, 40, $50,60,70,80,90,100,120,150$, and 180 min post glucose administration. Between each sample, the catheter and extension set were flushed with 15-20cc heparinized normal saline to prevent clot formation within the line, and avoid contamination of successive samples. Samples were placed in serum separator and sodium fluoride/potassium oxalate tubes (Vacutainer, Franklin Lakes, NJ), and stored on ice until centrifugation at $3000 \mathrm{x}$ g for $10 \mathrm{~min}$. Sodium fluoride/potassium oxalate additive was used to prevent further glycolysis in samples to be later assayed for glucose concentration. Aliquots were taken from both tubes, and stored in microcentrifuge tubes at $-2 \mathrm{C}$ until analysis. For insulin concentration, serum aliquots were measured in duplicate via a commercially available radioimmunoassay (Coat-A-Count, Siemens, Los Angeles, CA), as directed by the package insert. After the samples were decanted, they were placed in a gamma counter (Perkin Elmer, Wallac 1470 Wizard Auto Gammacounter, Waltham, MA), where each replicate was counted for 1 min. Plasma glucose was measured in duplicate using a commercially available kit (Autokit Glucose, Wako Diagnostics, Richmond, VA) adapted to a 96 well plate. In brief, $9 \mu \mathrm{L}$ of sample, 
standard or control were pipetted into a 96 well plate. Standards provided in the kit were diluted to include concentrations which more accurately reflect those seen in horse blood. ${ }^{158}$ Then, 3 L of buffer solution was added to each well, followed by $2 \mathrm{mi} \mathrm{n}$ incubation at 37 C The plate was then read on a UV spectrophotometer (Spectramax Plus 384, Molecular Devices, Sunnyvale, CA). Each of these kits have been previously validated for use in the horse. ${ }^{2,158}$ The accepted replicate coefficient of variation was 5\% and $10 \%$ for glucose and insulin concentrations, respectively. ${ }^{158}$

\section{Thiobarbituric Acid Reactive Substances (TBARS)}

Plasma samples collected on d 0 and 14 of each supplementation period were assayed for presence of TBARS. A commercially available kit (TBARS microplate assay kit, Oxford Biomedical Research, Oxford, MI) was used in accordance with the kit insert. In brief, $25 \mathrm{~L}$ of standard or sample was pipetted into a microcentrifuge tube, followed by $25 \mathrm{~L}$ of indicator solution or acid reagent. Samples were incubated at $5 \mathrm{C}$ for 15 min, then centrifuged at $100 \mathrm{xg}$ for $15 \mathrm{~min}$, and loaded onto a 96 well plate. Absorbance was read at 532nm (Flexstation3, Molecular Devices, Sunnyvale, CA). Samples containing acid reagent were used as a blank, and were subtracted from those containing indicator solution to determine malondialdehyde (MDA) concentration. Samples were assayed in duplicate.

\section{Data Analysis}

Area under the curve (AUC) for insulin and glucose was calculated via the trapezoidal method utilizing the data points from the FSIGT. ${ }^{158}$ Glucose effectiveness $(\mathrm{Sg})$, insulin sensitivity ( $\mathrm{Si}$ ), acute insulin response to glucose (AIRg) and disposition index (DI) were calculated using minimal model software (MinMod Millennium, Version 
6.02) as previously reported. ${ }^{20}$ Any animal which did not fit the model with an $\mathrm{R}^{2}>0.9$ was removed prior to statistical analysis.

Results are expressed as mean \pm SE. Data were analyzed using the GLM procedure of SAS (SAS Institute, Inc., Cary, NC, 2006) where horse was a random variable, and fixed variables included treatment, and period along with all possible interactions. The null hypothesis was rejected at $\alpha=.5 \mathrm{f}$ or main effects and interactions, with trends defined when $P \leq 0.10$. Treatments were further separated using Tukey's test where appropriate. Contrasts were also conducted within Proc GLM to examine differences between control $(\mathrm{C})$ and treatment ( $\mathrm{T}$, both low and high).

Body weights were averaged to determine mean weight across each $\mathrm{T}$ period. Daily hay and concentrate intake were evaluated in relationship to percent (\%) BW. Plasma TBARS concentrations were evaluated individually for $\mathrm{d} 0$ and 14 samples. Plasma TBARS data were also evaluated as normalized by subtracting the difference of $d$ 14 and $\mathrm{d} 0$ concentrations. 


\section{CHAPTER III - RESULTS}

\section{Body Weight and Feed Intake}

Results for mean BW were $541.81,540.46$, and $539.47 \pm 1.95 \mathrm{~kg}$ for $\mathrm{C}$, $\mathrm{L}$, and $\mathrm{H}$ respectively. No effect of treatment $(P=0.72)$, period $(P=0.36)$, or treatment by time interaction $(\mathrm{P}=0.29)$ was found.

Feed intake results were calculated based upon mean values of daily hay and concentrate intake, expressed as percent of BW consumed. Upon evaluation of hay intake, trends were noted with regard to treatment $(\mathrm{P}=0.097$, Figure 3$)$ and period $(\mathrm{P}=$ 0.094; Figure 4), but no interactions were observed $(\mathrm{P}=0.180)$. Hay intake averaged $1.66,1.71$, and $1.69 \pm 0.01 \% \mathrm{BW}$ in $\mathrm{kg}$ for $\mathrm{C}, \mathrm{L}$, and $\mathrm{H}$ respectively (Figure 3 ). The contrast between control and treatment groups showed a trend $(\mathrm{P}=0.053)$, where treatment resulted in an increased intake of $0.08 \% \mathrm{BW}$. Concentrate intake expressed as percent of BW displayed no significant effects of treatment $(P=0.122$, Figure 5), period $(\mathrm{P}=0.145)$ or interaction $(\mathrm{P}=0.217)$. Contrast evaluation between control and treatment groups revealed a trend $(\mathrm{P}=0.053)$, with treatment resulting in increased concentrate intake of $0.016 \%$ BW (Figure 5).

\section{TBARS}

Resveratrol treatment had no effect on plasma TBARS concentration after $14 \mathrm{~d}$ of supplementation $(\mathrm{P}=0.61$; Figure 6$)$. Period also did not have an effect on plasma TBARS concentration $(P=0.83)$ and no interaction was noted $(P=0.99)$. Plasma TBARS normalized for $\mathrm{d} 0$ concentration also did not differ between treatments $(\mathrm{P}=$ $0.40)$ or periods $(\mathrm{P}=0.93)$ and no interactions were observed $(\mathrm{P}=0.86)$. 


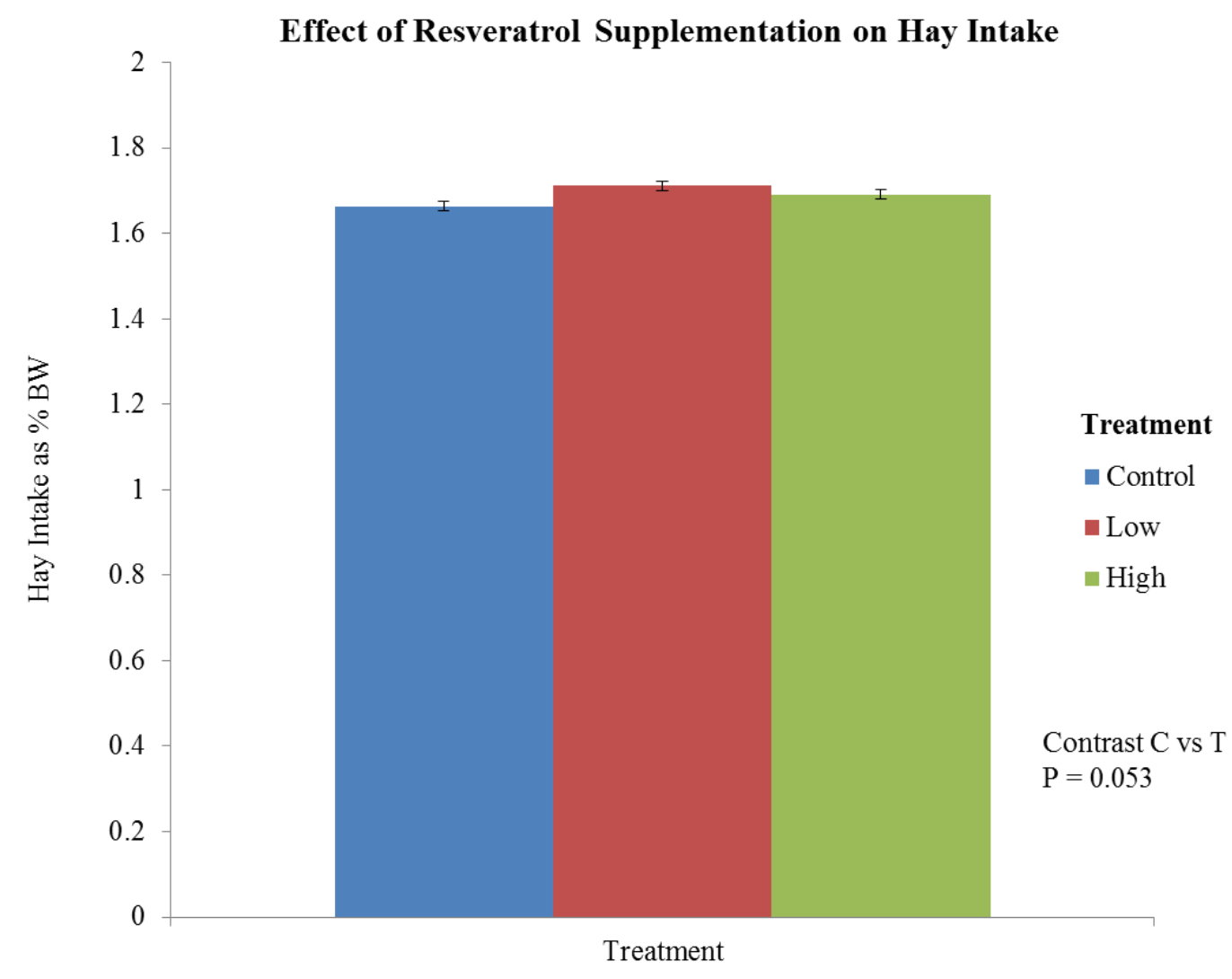

Figure 3: Hay intake expressed as \% of BW $(\mathrm{kg})$ of mature Quarter Horse geldings $(\mathrm{n}=$ 6 , mean $\pm \mathrm{SE})$ in relation to resveratrol supplementation at low $(\mathrm{L})$ or high $(\mathrm{H})$ dosage, or no supplementation (control C). Each period lasted 2 weeks. Trends are denoted with brackets and symbols, where $\mathrm{P}<0.10$. Contrasts are defined as $\mathrm{C}$ versus treatment $(\mathrm{L}$ and $\mathrm{H}$ resveratrol supplementation). 


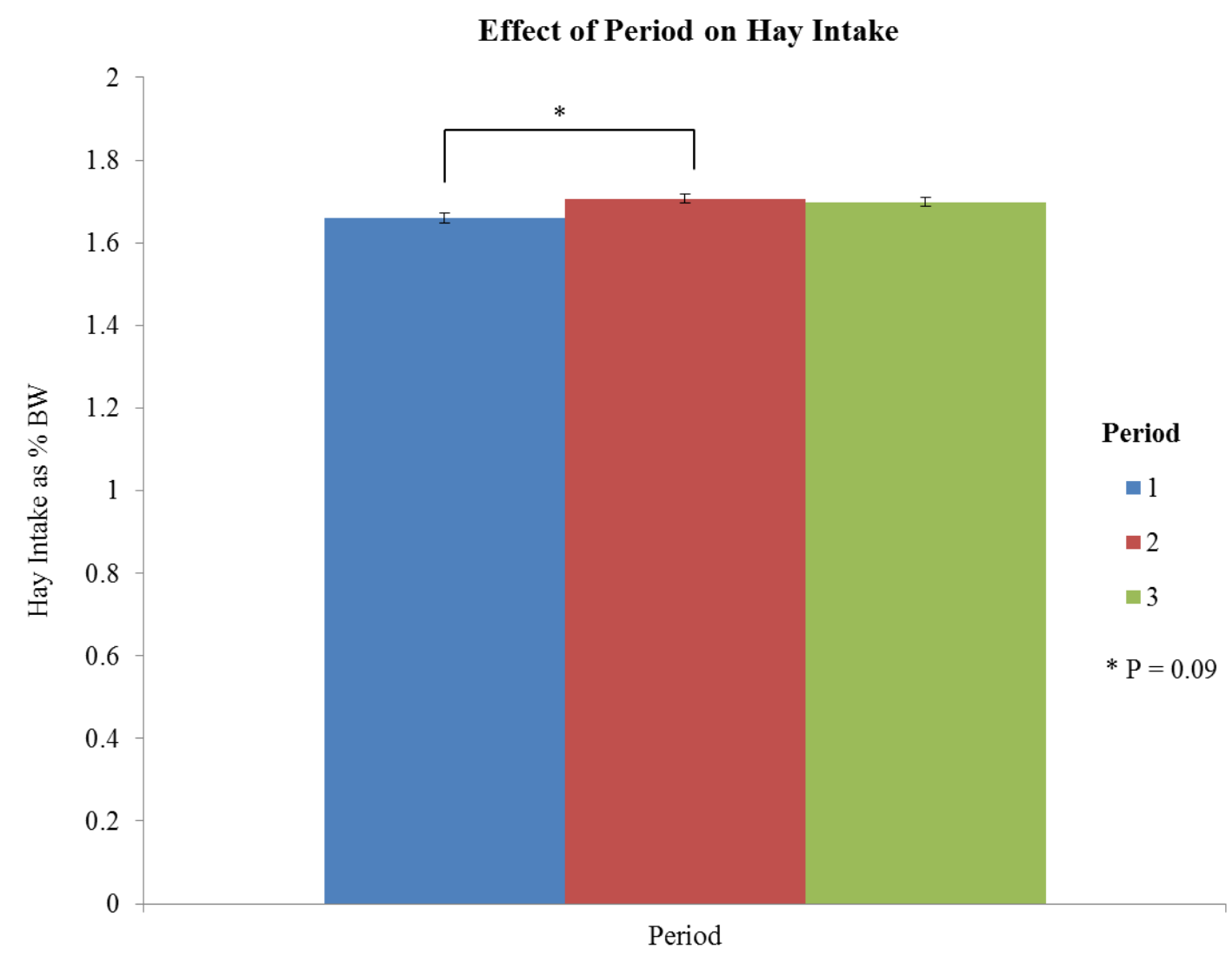

Figure 4: Hay intake expressed as \% of BW $(\mathrm{kg})$ of mature Quarter Horse geldings ( $\mathrm{n}=$ 6 , mean $\pm \mathrm{SE}$ ) in relation to period during resveratrol supplementation at low (L) or high (H) dosage, or no supplementation (control C). Each period lasted 2 weeks. Trends are denoted with brackets and symbols, where $\mathrm{P}<0.10$. 


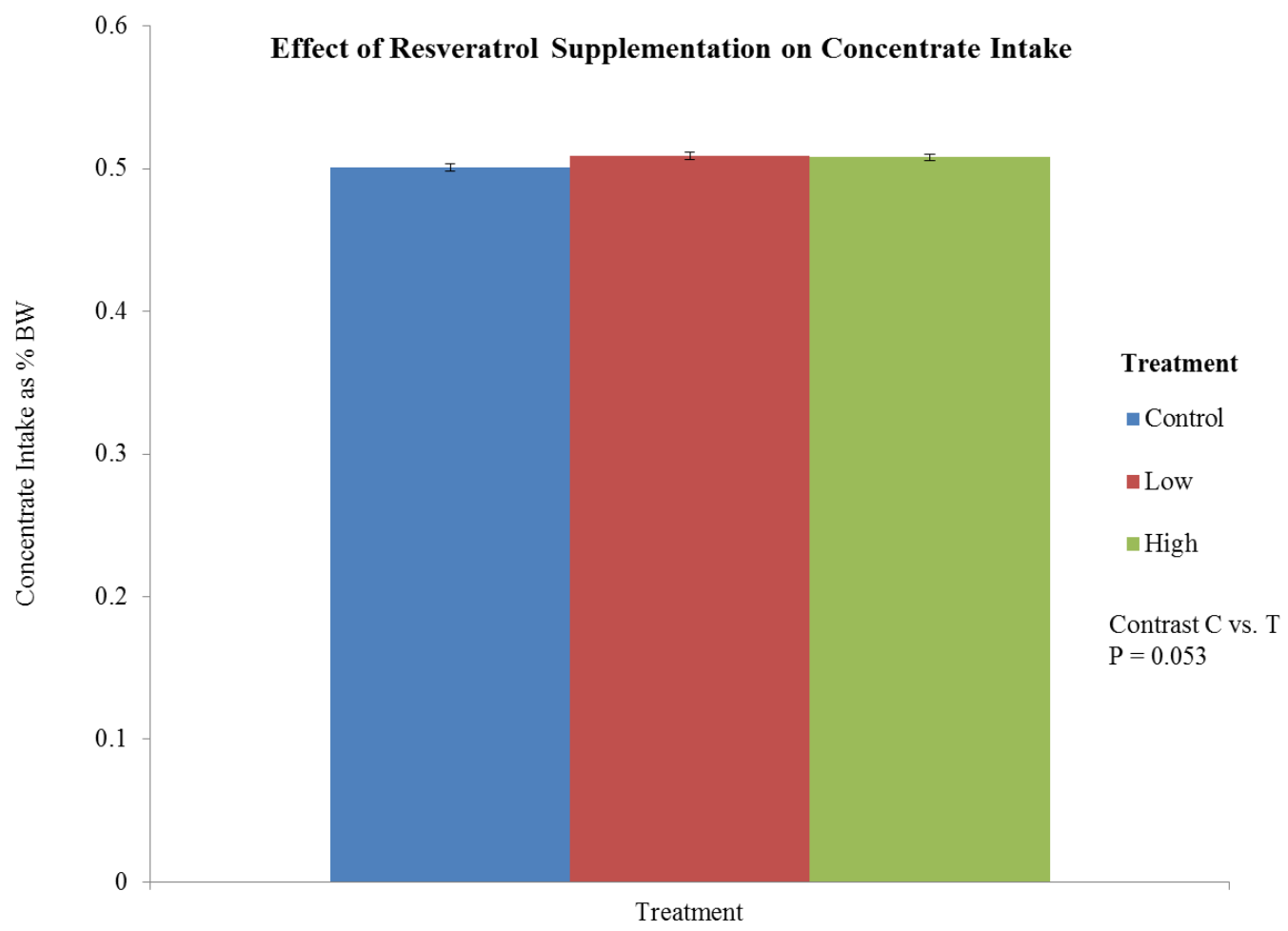

Figure 5: Concentrate intake expressed as \% of BW (kg) of mature Quarter Horse geldings $(n=6$, mean $\pm S E)$ in relation to resveratrol treatment over 3 periods, lasting 2 weeks each. Trends are denoted with regard to contrasts, which are defined as $\mathrm{C}$ versus treatment ( $\mathrm{L}$ and $\mathrm{H}$ resveratrol supplementation), where $\mathrm{P}<0.10$. 


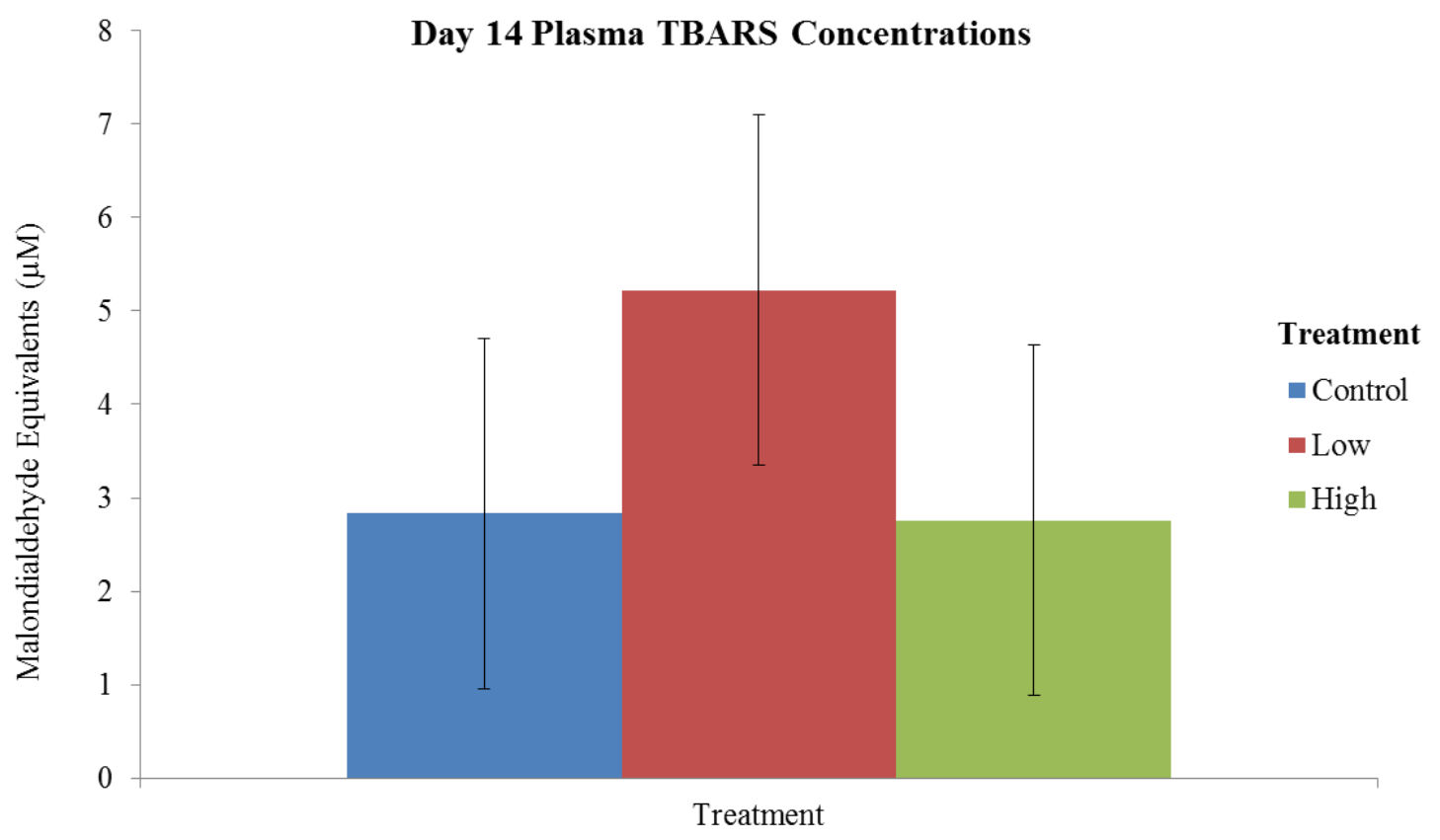

Figure 6: Plasma TBARS concentrations (mean \pm SE) for 6 mature Quarter Horse geldings on d 14 of supplementation with low $(\mathrm{L})$ or high $(\mathrm{H})$ dose of resveratrol or control (C, no supplementation). Plasma TBARS is expressed as malondialdehyde (MDA) equivalents. No trends or significant differences are noted for treatment $(\mathrm{P}=$ $0.61)$, period $(\mathrm{P}=0.83)$ or interactions $(\mathrm{P}=0.99)$. 
There were no differences in baseline insulin concentrations between treatment groups $(\mathrm{P}=0.26)$, period $(\mathrm{P}=0.99)$, or interactions $(\mathrm{P}=0.36)$. Baseline plasma glucose also did not differ in regards to treatment $(\mathrm{P}=0.89)$, period $(\mathrm{P}=0.56)$, or interaction $(\mathrm{P}=$ 0.34; Figure 7 and 8).

A representative glucose and insulin curve for $\mathrm{C}, \mathrm{L}$, and $\mathrm{H}$ treatment can be found in Figures 9, 10, and 11, respectively. Curves were accepted for graphical representation based upon their fit into the minimal model $\left(\mathrm{R}^{2}>0.9\right)$.

There were no differences between treatment $(\mathrm{P}=0.56)$, period $(\mathrm{P}=0.41)$, and no interaction $(P=0.20)$ were noted with regard to $\mathrm{Sg}$. Similarly, Si was not affected by treatment $(\mathrm{P}=0.59)$, period $(\mathrm{P}=0.14)$ or interaction $(\mathrm{P}=0.79)$. Treatment, period, nor interaction had an effect on $\mathrm{AIRg}$, where $\mathrm{P}=0.35,0.98$, and 0.43 respectively. Disposition index (DI) was also not affected by treatment $(\mathrm{P}=0.93)$ or period $(\mathrm{P}=0.19)$ and no interaction was displayed $(\mathrm{P}=0.84)$. No differences between treatment $(\mathrm{P}=$ $0.84)$, period $(\mathrm{P}=0.32)$, or interaction $(\mathrm{P}=0.95)$ were noted with regard to AUC of insulin. Likewise, AUC of glucose did not differ in regards to treatment $(\mathrm{P}=0.80)$, period $(\mathrm{P}=0.82)$ or interaction $(\mathrm{P}=0.97) . \quad$ A summary of the data can be found in Table 3. 


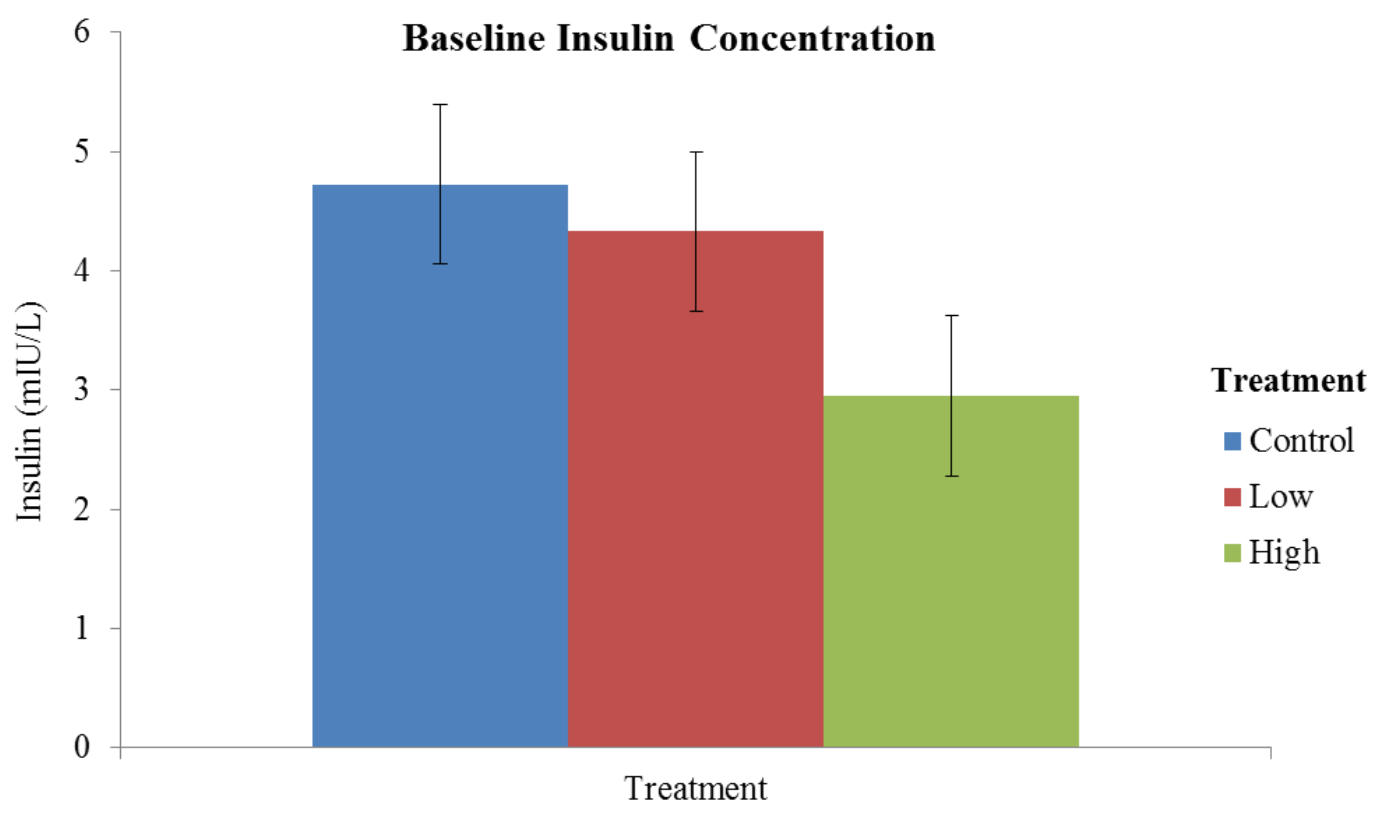

Figure 7: Baseline insulin concentration (mean $\pm \mathrm{SE}$ ) after an overnight fast in six mature Quarter Horse geldings supplemented with resveratrol (low or high dose), or control (no supplementation). No significant effects or trends of treatment $(\mathrm{P}=0.26)$, period $(\mathrm{P}=0.99)$ or interactions $(\mathrm{P}=0.36)$ were noted. 


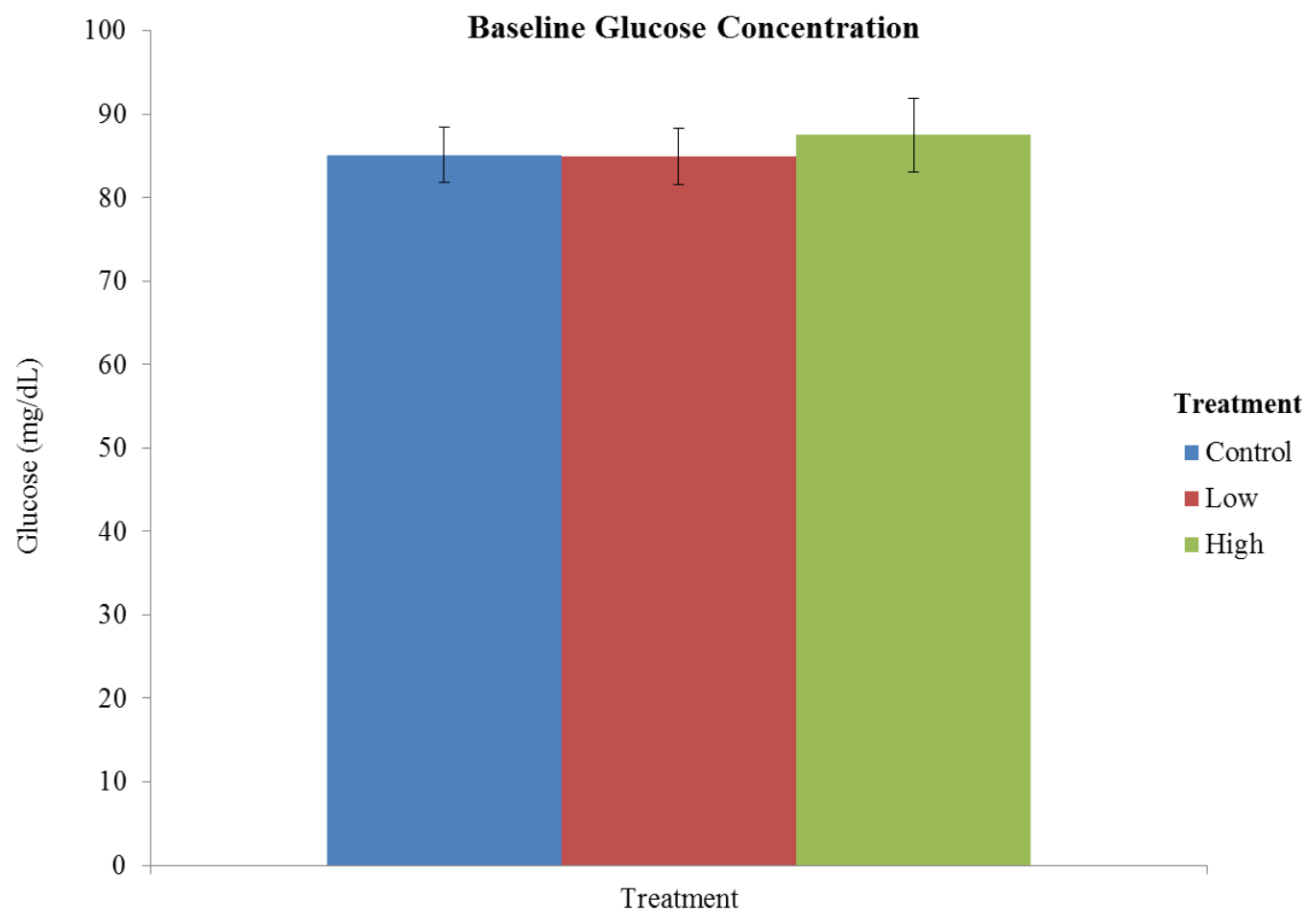

Figure 8: Basal glucose concentration (mean $\pm \mathrm{SE}$ ) in six mature Quarter Horse geldings sampled after an overnight fast and supplemented with resveratrol (low, L, or high, $\mathrm{H}$, dose), or control ( $\mathrm{C}$, no supplementation). No effects or trends of treatment $(\mathrm{P}=0.89)$, period $(\mathrm{P}=0.56)$ or interactions ( $\mathrm{P} 0.34)$ were noted. PVALUES 


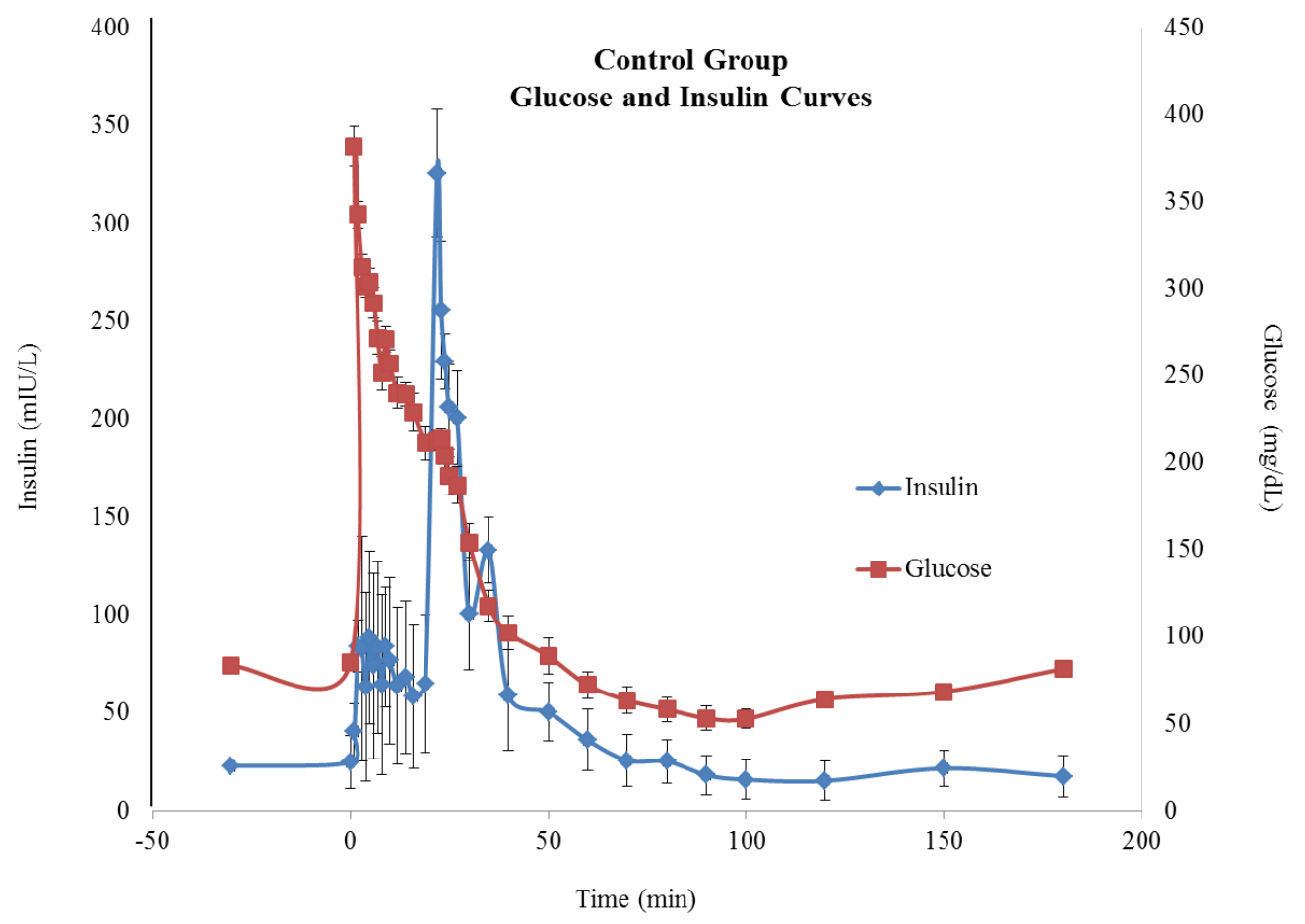

Figure 9: Mean glucose and insulin concentrations (mean \pm SE) from a frequently sampled intravenous glucose tolerance test (FSIGT) for the control (C, no supplementation) horses $(\mathrm{n}=6)$ over 3 periods lasting 2 weeks each are displayed. Data was collected and utilized for graphical representation when $\mathrm{R}^{2}>0.9$. 


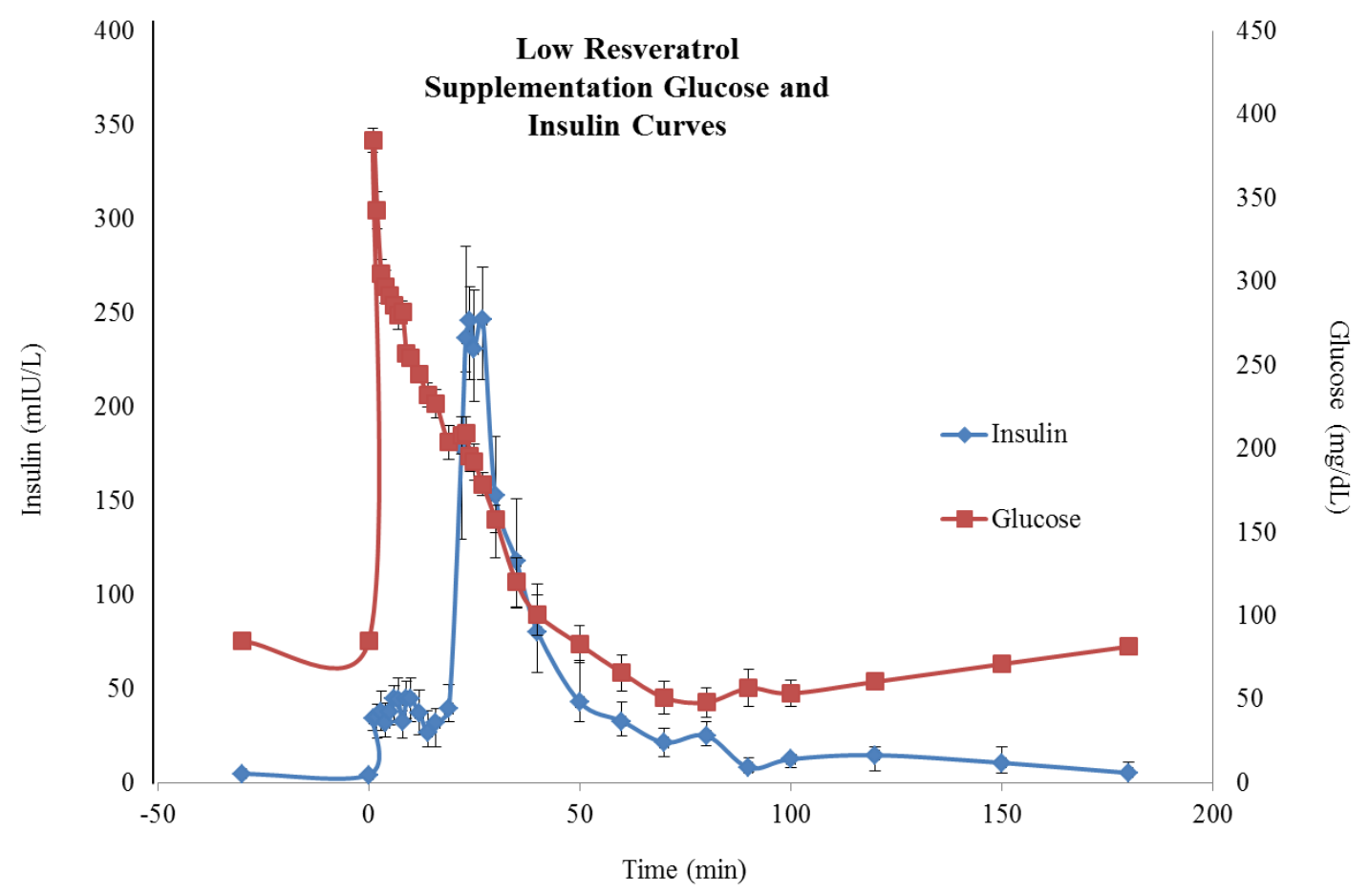

Figure 10: Mean glucose and insulin concentrations (mean \pm SEM) from a frequently sampled intravenous glucose tolerance test (FSIGT) for the low (L) dose resveratrol supplemented horses $(\mathrm{n}=6)$ over 3 periods lasting 2 weeks each are displayed. Data was collected and utilized for graphical representation when $\mathrm{R}^{2}>0.9$. 


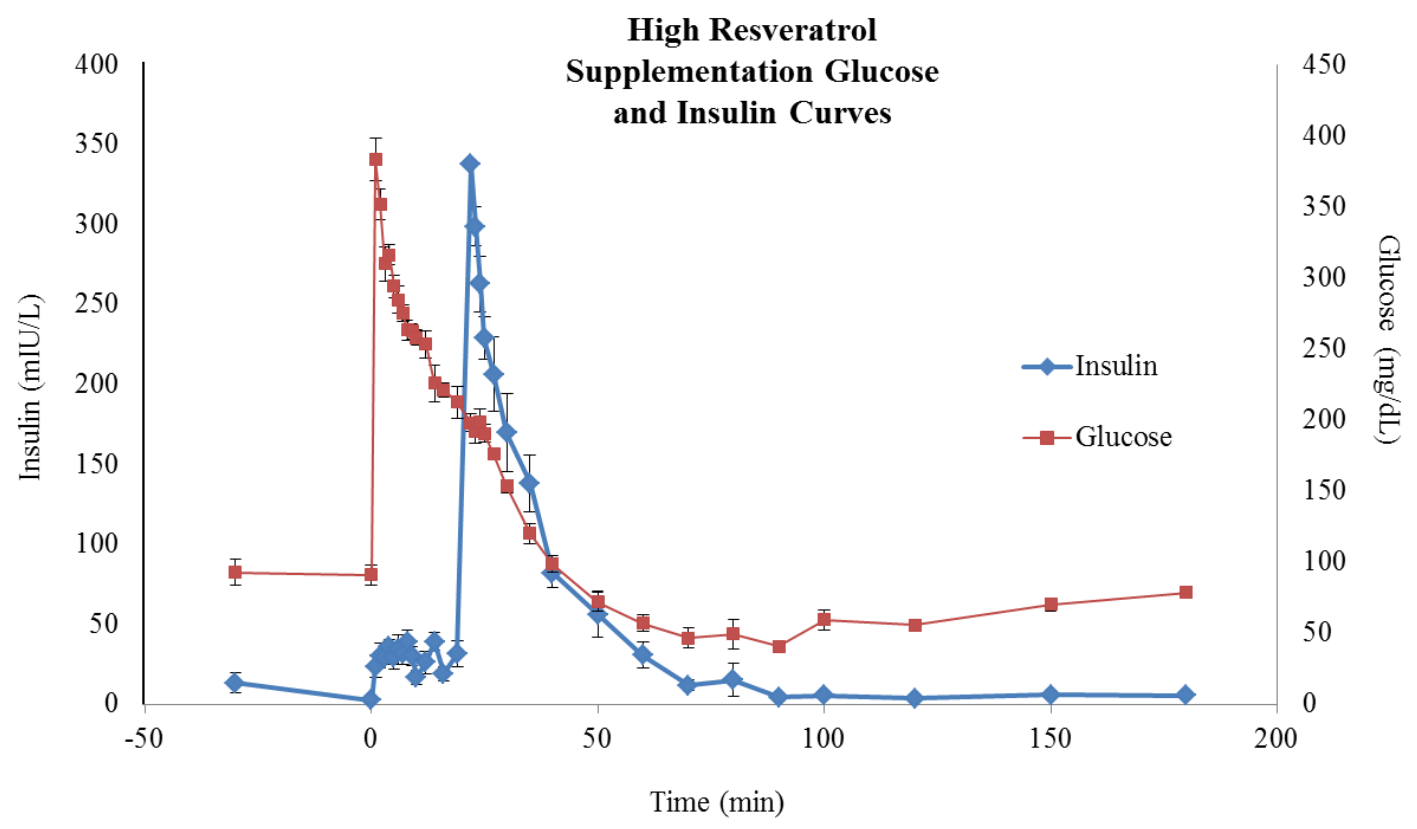

Figure 11: Mean glucose and insulin concentrations $($ mean $\pm \mathrm{SE})$ from a frequently sampled intravenous glucose tolerance test (FSIGT) for the high $(\mathrm{H})$ dose resveratrol supplemented horses $(n=6)$ over 3 periods lasting 2 weeks each are displayed. Data was collected and utilized for graphical representation when $\mathrm{R}^{2}>0.9$. 


\section{Basal Glucose Concentration (Gb)}

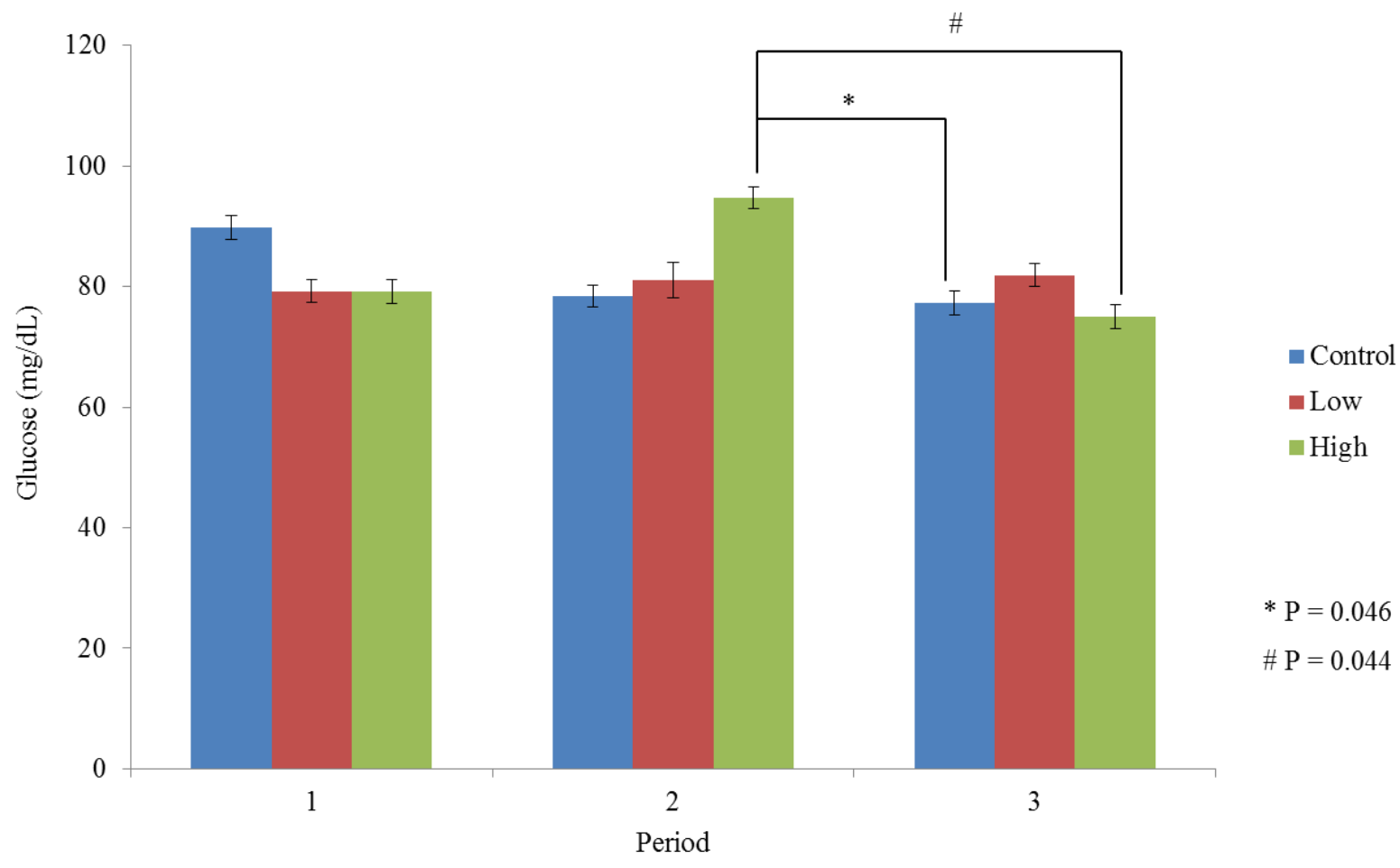

Figure 12: Basal glucose $(\mathrm{Gb})$ concentrations (mean $\pm \mathrm{SE})$ from a frequently sampled intravenous glucose tolerance test (FSIGT) were calculated based on control (C, no supplementation), low resveratrol supplementation (L) or high resveratrol supplementation $(\mathrm{H})$. Basal glucose is utilized conjunction with the minimal model parameters. Significant interactions are noted with brackets and symbols. 
Table 3: Least squares means \pm SE for Minimal Model variables and area under the curve (AUC) for glucose and insulin in regard to control (C, no supplementation), low (L), or high $(\mathrm{H})$ dose resveratrol supplementation in 6 mature Quarter Horse geldings in response to a frequently sampled intravenous glucose tolerance test (FSIGT).

\begin{tabular}{|c|c|c|c|c|c|}
\hline \multirow{2}{*}{$\begin{array}{l}\text { Glucose \& Insulin } \\
\text { Parameters }\end{array}$} & \multicolumn{3}{|c|}{ Treatment } & \multicolumn{2}{|c|}{ Pvalue } \\
\hline & Control & Low & High & Treatment & Contrast $(\mathrm{C}$ vs $\mathrm{T})$ \\
\hline $\operatorname{Sg}\left(\min ^{-1}\right)$ & $0.030 \pm 0.003$ & $0.032 \pm 0.004$ & $0.035 \pm 0.003$ & 0.56 & 0.43 \\
\hline $\mathrm{Si}\left(\mathrm{L}^{*} \mathrm{mU}^{-1 *} \min -{ }^{1}\right)$ & $5.93 \pm 1.77$ & $7.83 \pm 2.33$ & $8.70 \pm 1.77$ & 0.59 & 0.38 \\
\hline $\operatorname{AIRg}\left(m U^{*} \min * L^{-1}\right)$ & $303.87 \pm 20.84$ & $332.58 \pm 27.56$ & $272.03 \pm 20.84$ & 0.34 & 0.96 \\
\hline DI & $2091.50 \pm 647.51$ & $2203.60 \pm 856.57$ & $2439.50 \pm 647.51$ & 0.93 & 0.8 \\
\hline AUC Glucose (mg/dl * min) & $20432.72 \pm 1240.75$ & $19301.89 \pm 1240.75$ & $19505.60 \pm 1240.75$ & 0.80 & 0.54 \\
\hline AUC Insulin (mIU/L * min) & $7056.79 \pm 992.33$ & $6666.44 \pm 992.33$ & $6213.05 \pm 992.33$ & 0.84 & 0.64 \\
\hline
\end{tabular}




\section{CHAPTER IV - DISCUSSION}

This work presents the results from a controlled study in which six moderately exercised mature Quarter Horse geldings were supplemented with resveratrol to determine if treatment affected glycemic response and oxidant status.

Resveratrol supplementation administered during this study was compounded with polyethylene glycol. Although the $\mathrm{C}$ group (no supplementation) did not receive any vehicle supplementation, energy substrates present in this compound add a negligible amount to overall dietary components, and thus should not have had an effect on body condition or energy status between $\mathrm{C}$ and $\mathrm{T}$ groups.

\section{Body Weight and Feed Intake}

Prior to the start of the study, horses were housed in an approximately 12 acre pasture, and were utilized in West Virginia University's Equestrian Technology course. Horses were exercised lightly, mainly utilized for beginner to intermediate riding classes, 3 times per week. As an athletic horse, feed intake is important to ensure digestible energy needs are met, especially for horses with little preference for forage. Contrast between $\mathrm{C}$ and $\mathrm{T}$ demonstrate a potential use for resveratrol to increase feed intake in the moderately exercised equine athlete. Increased levels of forage may provide a potential benefit to the horse, as increased forage intake can lead to increased energy substrate from hindgut fermentation and perhaps even an elevated hydration status. ${ }^{159}$ A period effect was noted, with low hay consumption in the first period which may be attributable to preference for pasture previously consumed over the hay being offered in the initial days. Also, human error may have been a factor, as collection of daily refusals may have 
differed slightly from person to person. This could provide a potential benefit to the athletic horse. While, the current aim of the study was not to evaluate effects effects of resveratrol on body mass or composition, an increased intake attributable to supplementation was noted. Within a moderate body condition, resveratrol has no effect on body weight, but may have some use in increasing feed intake in the exercising horse, although intake was minimal in comparison to overall daily intake.

\section{TBARS}

Resveratrol supplementation at low and high levels did not have an effect on plasma TBARS (MDA concentration) in plasma. Other markers of oxidant status such as glutathione, glutathione peroxidase, and nitric oxide were considered for this study, however due to kit inconsistency with equine tissue and blood samples, they were not used for this study. Still, speculation into the validity of the TBARS test must be considered. Plasma TBARS is utilized to determine lipid peroxidation through the entire body; however, the limitations with this assay must be noted. TBARS utilizes MDA, a by-product of lipid peroxide to determine the amount of oxidation that occurred. Oxidative stress has been shown to occur with specific modes of exercise, yet severity and level of tissue damage have not always been consistent, even when similar exercise and collection protocols are used. ${ }^{160}$ Large variation within this assay for equine models has been noted numerous times, ${ }^{117,160,161}$ with pre-exercise ranges measuring from 66 to $1048 \mathrm{nmol} / \mathrm{L},{ }^{161}$ and an apparent $\mathrm{CV}$ of $>40 \% .{ }^{160}$ Variations between studies including diet, age, previous training history, and analytical methods may play a role in this inconsistency. ${ }^{162-164}$ 
Elevated levels of plasma and serum TBARS have been observed after strenuous exercise; ${ }^{165,166}$ yet, other research has shown long term exercise and acute physical activity have not altered plasma TBARS concentration. ${ }^{167}$ Prolonged low-medium intensity exercise has been the most frequently used exercise type to induce marked oxidative stress in humans. ${ }^{168,169}$ In half marathon runners, an increase in plasma TBARS of $600 \mathrm{nmol} / \mathrm{L}$ after 40 minutes exercise at $40 \% \mathrm{VO}_{2 \max }$ was seen, ${ }^{178}$ but no increase in TBARS was noted after a full marathon was completed. ${ }^{171}$ Horses that completed a simulated race of $1000 \pm 200 \mathrm{~m}$ at an approximate speed of $16 \mathrm{~m} / \mathrm{s}$ displayed an increase in plasma TBARS $(\mathrm{P}<0.01),{ }^{161}$ and lipid peroxidation was higher in horses finishing an $80 \mathrm{~km}$ endurance race when compared to those having finished only 21 km. ${ }^{117}$ While these results suggest that exercise should increase plasma TBARS concentration as a reflection of increased lipid peroxidation, this study did not display a similar result. During this study, horses were exercised at a moderate intensity during each period. Although the exercise protocol was designed to be challenging to the horses, the study design was not to determine effects of resveratrol on tolerance to an acute exercise bout, but rather to determine if treatment would be beneficial to the conditioned athletic horse. Marketing of resveratrol is currently aimed at the performance horse, with claimed applications to those horses exercising at a moderate level, therefore; in order to determine resveratrol effectiveness at this level of performance, exercise intensity was held constant through the study. Perhaps if a more strenuous exercise test was included with either an increased intensity, duration or both had been implemented, an increase in plasma TBARS would have been observed. 
Literature mainly reports MDA concentration within plasma or serum, ${ }^{172}$ yet not in skeletal muscle, which may provide a more accurate depiction of lipid peroxidation occurring at the tissue level. Consideration must be given to the collection methods for muscle tissue, as the biopsy procedure may increase damage to the sample. In comparison to blood parameters, there are few studies utilizing muscle currently available, with inconclusive results. In sedentary rats a slight increase in TBARS has been shown in response to exhaustive exercise, ${ }^{164,173}$ yet others have shown light to moderate acute exercise bouts have not altered TBARS concentration at the tissue level, without comparison to blood values. ${ }^{174}$ Further research is needed to validate testing techniques, especially in an equine model and thus, TBARS was not evaluated in muscle samples.

Sampling time after exercise may also affect reported TBARS concentrations. Mixed information is available regarding the rates of production and clearance of TBARS from the body, making sampling difficult. Human strength training studies commonly sample 24 and $48 \mathrm{~h}$ post exercise ${ }^{165}$, yet other studies have shown decreases after an acute exercise bout as soon as $30 \mathrm{~m}$ post exercise, with returns to baseline $\sim 1 \mathrm{~h}$ after exercise. ${ }^{165}$ Equine studies report varying sampling times as well, with samples taken during exercise ${ }^{117}$ as well as anywhere from $5 \min ^{161}$ to $16 \mathrm{~h}^{160}$ and as far out as $2 \mathrm{wk}$ post exercise. ${ }^{175}$ During this study, samples were collected $\sim 24 \mathrm{~h}$ after an exercise bout to be assayed for TBARS concentration. Intensity and duration of exercise may not have been sufficient to elicit a detectable change in TBARS during this timeframe, or TBARS may have returned to baseline by sample time. It is possible if samples had been collected closer to the completion of exercise, or if an acute exercise bout had been conducted, 
differences may have been seen. Therefore, further work needs to be done to determine if resveratrol has an effect on lipid peroxidation during or immediately following an acute exercise bout.

Evaluation of other markers may have provided a more selective view of the function of resveratrol within the horse, but for the purpose of this study, the TBARS assay was to be used as an informative comprehensive parameter as to the effects of resveratrol supplementation in an exercising athlete. Along with the limitations mentioned above, assessment of the antioxidant enzyme pathways present in the body were not measured, and therefore their contribution to preventing lipid peroxidation cannot be determined. Resveratrol may impact these pathways as well, and further information needs to be collected to elucidate its role for the equine athlete in various types of exercise.

\section{Glucose Tolerance and Insulin Sensitivity}

Previously, resveratrol has been shown to enhance insulin stimulated glucose transport, via up-regulation of GLUT 4, and improved glucose tolerance. ${ }^{8}$ Data from this study shows resveratrol supplementation has no effect on glucose tolerance and insulin sensitivity represented through Minimal Model analysis, nor baseline insulin and glucose concentrations. Causes for this discrepancy may be due to the model utilized for the study, along with body condition of the horses. Individual variability with regard to treatment must also be considered, as each horse's response to treatment may have been different with regard to starting metabolic efficiency, and even sensitivity to the compound. 
Both single bouts and prolonged repetitive aerobic exercise has been shown to increase insulin sensitivity and glucose tolerance through sensitization of target tissues to insulin, along with increased translocation of GLUT 4 via enhanced cellular signalling. ${ }^{112-114}$ In the moderately exercised fit horse, optimum insulin signaling pathways should already be in place, thereby making changes to an optimum system difficult to produce. An increased presence of mitochondria within the cell due to exercise-induced mitochondrial biogenesis make the muscle cell more energetically efficient, while allowing for increased cellular oxidative respiration. ${ }^{176}$ Having these systems already in place and being conditioned to exercise leaves little room for resveratrol to impact these pathways. Perhaps, if an obese or unfit model was utilized, placed into a similar study and evaluated for increased insulin sensitivity and glucose tolerance, different results may have been displayed. Obesity is seen as an increase in body condition score, which has been proven to decrease insulin sensitivity, thereby impacting glucose metabolism. ${ }^{8}$ Obese horses were found to have a lower Si and relied primarily on Sg for glucose disposal, rather than insulin signaling pathways. ${ }^{20}$ This disease state rather than an athletic model may be a potential niche for resveratrol supplementation from a glucose tolerance standpoint, due to its potential ability to increase insulin sensitivity and increase effectiveness of this mechanism. ${ }^{150}$ Resveratrol may impact various parameters of the Minimal Model, including Si, AIRg and DI for its properties relating to increasing tissue sensitivity to insulin, enhancement of pancreatic $\beta$ cell function, and the body's ability to mediate its own insulin response.

At the same time, resveratrol is known to up-regulate SIRT1 gene expression and down regulate PPAR $\gamma$, together which influence the utilization of fat as an energy 
substrate, along with inhibition of inflammatory status, both of which may help to modulate the confounding aspects of insulin resistance seen with obesity. ${ }^{123,152,157}$ Increasing oxidation of lipids as a fuel source may also be beneficial to the endurance athlete, which may be a potential model for further investigation, while reduction in inflammation may prove useful in athletic horses experiencing osteoarthritis and other orthopedic injuries. 


\section{CONCLUSIONS}

Resveratrol supplementation in moderately exercised horses resulted in few apparent effects. Trends toward increased feed intake expressed as a percent of BW from resveratrol supplementation may be cause for further investigation for the performance animal; however, it is important to consider the small amount of feed intake seen in regard to resveratrol supplementation when compared to the total amount of intake per

day. Resveratrol supplementation has no effect on glycemic and insulinemic responses as tested by a FSIGT, along with baseline insulin and glucose concentrations, in this exercising equine model. Plasma TBARS was also unaffected by supplementation; however, a more in depth evaluation of the actions of resveratrol in the exercising model is needed to discern its functions among antioxidant enzyme activity. From this study, the marketing of resveratrol as a supplement to increase glucose tolerance and reduce ROS damage in performance horses is not supported. Evaluation of resveratrol within a different athletic model, such as endurance exercise or ability to tolerate acute exhaustive bouts of exercise, with regard to fat metabolism, oxidant status, and inflammation may uncover other beneficial functions of resveratrol not assessed here. Therefore, further research is needed to more thoroughly examine the possible effects of resveratrol supplementation in the horse. 


\section{LITERATURE CITED}

1. Turrens JT. Topical Review: Mitochondrial formation of reactive oxygen species. J Physiol: 2003. 552.2:335-344.

2. Halliwell B, Gutteridge J. Free radicals in biology and medicine. Oxford Press, Oxford. 2007.

3. McKeever KH, Hinchcliff KW, Reed SM, et al. Role of decreased plasma volume in hematocrit alterations during incremental treadmill exercise in horses American Journal of Applied Physiology. 1993;25:233-236.

4. Williams CA, Lamprecht ED. Some commonly fed herbs and other functional foods in equine nutrition: A review. The Veterinary Journal. 2008;178:21-31.

5. Wadsworth TL, Koop DR. Effects of the wine ployphenolics Quercetin and Resveratrol on pro-inflammatory cytokine expression in RAW 264.7 macrophages. Biochemical Pharmacology. 1999;57:941-949.

6. Rivera L, Moron R, Zarzuelo A, Galisteo. Long-term resveratrol administration reduces metabolic disturbances and lowers blood pressure in obese Zucker rats. Biochemical Pharmacology 2009;77:1053-1063.

7. Hinchcliff KW, Geor RJ. Equine Exercise Physiology: The science of exercise in the athletic horse. Chapter 1.1:The horse as an athlete-a physiological overview. 2008; Elsevier:2-11.

8. Dirks-Naylor AJ. Cellular effects of resveratrol in skeletal muscle. Life Sciences 2009;84:637-640.

9. Park CE, Kim MJ, Lee JH, Min BI, Bae H, Choe W, Kim SS, Ha J. Resveratrol stimulates glucose transport in $\mathrm{C} 2 \mathrm{C} 12$ myotubes by activating AMPactivated protein kinase. Experimental Molecular Medicine 2007;39:222-229.

10. Jones JH, Longworth KE, Lindholm A, et al. Oxygen transport during exercise in large mammals. I. Adaptive variation in oxygen demand. Journal of Applied Physiology. 1989;67:862-870.

11. Persson SDG. On blood volume and working capacity of horses. Acta Physiologica Scandanavia. 1967; supplement 19:9-189.

12. Kayar SR, Hoppeler H, Lindstedt, et al. Total muscle mitochondrial volume in relation to aerobic capacity of horses and steers. Pflugers Archive: European Journal of Physiology. 1989;413:343-347.

13. Geor RJ, Hinchcliff KW, Sams R. Glucose infusion attenuates endogenous glucose production and enhances glucose use of horses during exercise. Journal of Applied Physiology. 2000;88:1765-1776.

14. Pagan JD. Carbohydrates in equine nutrition. Kentucky Equine Research Inc. 1996:41. 
15. Hoffman RM. Recent advances in equine nutrition: Carbohydrate metabolism in horses. 2003:International Veterinary Information Service.

16. Ralston SL. Hyperglycemia/ Hyperinsulinemia after feeding a meal of grain to young horses with OCD. Pferdeheilkundle 12:320-322.

17. Shirazi-Beechey SP. Molecular biology of intestinal glucose transport. Nutritonal Research Review 1995; 8:27-41.

18. James DE. The mammalian facilitative glucose transporter family. News Physiolology and Science 1995; 10:67-71.

19. Schulman, Bloch, et al. In vivo regulation of muscle glycogen synthase and the control of glycogen synthesis. Procceedings of the National Academy of the Sciences. 1995;92:8535-8524.

20. Hoffman RM, Boston RC, Stefanowski D, Kronfeld DS, Harris PA. Obesity and diet affect glucose dynamics and insulin sensitivity in Thoroughbred geldings. 2003;81:2333-2342.

21. Yki-Jarvinen H. Glucose toxicity. Endocrinology review. 1992;3:415-431.

22. Valberg S, Firshman A. Insulin resistance: What is it and how do we measure it? Kentucky Equine Research, Inc. 2009:335-366.

23. Straub SG, Sharp GW. Glucose-stimulated signaling pathways in biphasic insulin secretion. Diabetes Metabolism Research Review. 2002;18:451-63.

24. Watson, Pessin. Intracellular organization of insulin signaling and GLUT4 transloacation. The Endocrine Society. 2001;56:175-193.

25. McManus EJ, Sakamoto K, Armit LJ, Ronaldson L, Shpiro N, Marquez R, Alessi DR. Role that phosphorylation of GSK3 plays in insulin and Wnt signalling defined by knockin analysis. The EMBO Journal. 2005; 24:1571-1583.

26. Goodyear, Kahn. Exercise, glucose transport and insulin sensitivity. Annual Review of Medicine 1998. 49:235-61.

27. Kronfeld D. Insulin signaling laminitis and exercise. Journal of Equine Veterinary Science. 2005;25:404-407.

28. Pacini G, and Bergman RN. MINMOD: a computer program to calculate insulin sensitivity and pancreatic responsivity from frequently sampled intravenous glucose tolerance tests. Computer methods and programs in biomedicine. 1986;23:113-122.

29. Kronfeld DM, Treiber K, Hess T, Boston R. Insulin resistance in the horse: definition, detection and dietetics. Journal of Animal Science 2005;83:E2231.

30. Firshman AM, Valberg SJ. Review Article; Factors affecting clinical assessment of insulin sensitivity in horses. Equine Veterinary Journal. 2007;39:567-575.

31. Roberts MC, Hill FWG. The oral glucose tolerance test in the horse. Equine Veterinary Journal. 1973;5:171-173. 
32. Breukink HJ. Oral mono- and disaccharide tolerance tests in ponies. American Journal Veterinary Research. 1974;35:1523-1527.

33. Jacobs KA, Bolton JR. Effect of diet on the oral glucose tolerance test in the horse. Journal of the American Veterinary Medical Association. 1982;180:884-886.

34. June V, Soderholm V, Hintz HF, Butler WR. Glucose tolerance in the horse, pony and donkey. Equine Veterinary Science. 1992;12:103-105.

35. Kanecko JJ. Carbohydrate metabolism and its diseases. In: Kanecko JJ, Harvey JW, Bruss ML eds. Clinical Biochemistry of Domestic Animals, $4^{\text {th }}$ ed. Academic Press Inc., San Diego. 1989:44-81.

36. Ralston SL. Insulin and glucose regulation. Veterinary Clinics in North America: Equine Practice. 2002;18:295-304.

37. Kronfeld DS, Treiber KH, Hess TM, Splan RK, Byrd BM, Staniar WB, White NW. Metabolic syndrome in heathy ponies facilitates nutritional countermeasures against pasture laminitis. Jounral of Nutrition. 2006;136:2090S2093S.

38. Argenzio RA, Hintz HF. Glucose tolerance and effect of volatile fatty acid on plasma glucose concentrations in ponies. Journal of Animal Science. 1970;30:666-674.

39. Mehrig JS, Tynzig WJ. Equine glucose tolerance. Journal of Animal Science. 1970;30:764-766.

40. Ribiero WP, Valberg SJ, Pagan JD, Gustavsson BE. The effect of varying dietary starch and fat content on serum creatine kinase activity and substrate availability in equine polysaccharide storage myopathy. Journal of Veterinary Internal Medicine. 2004;18:887-894.

41. Vick MM, Sessions DR, Murphy BA, Kennedy EL, Reedy SE, Fitzgerald BP. Obesity is associated with altered metabolic and reproductive activity in the mare: Effects on metformin on insulin sensitivity and reproductive cyclicity. 2006;18:609-617.

42. Treiber KH, Kronfeld DS, Hess TM, Byrd BM, Splan RK, Staniar WB. Evaluation of genetic nd metabolic predispositions and nutritional risk factors for pasture-associated laminitis in ponies. 2006;228:1538-1545.

43. Giraudet A, Hinchcliff KW, Kohn CW, McKeever KH. Early insulin response to an intravenous glucose tolerance test in horses. American Journal of Veterinary Research. March, 1994. 55(3):379-381.

44. Liburt NR, Fugaro MN, Wunderlich EK, Zambito JL, Horohov DW, Betancourt A, Boston RC, McKeever KH, Goer RJ. Fat and muscle tissue cytokine profiles, body composition and insulin sensitivity of old and young standardbred mares before and after exercise training. Under Review JAS. 
45. Kronfeld DS, Treiber KH, Geor RJ. Comparison of nonspecific indications and quantitative methods for the assessment of insulin resistance in horses and ponies. Journal of American Veterinary Medical Associates. 2005;226:712-719.

46. Treiber KH, Kronfeld DS, Geor RJ. Insulin resistance in equids: Possible role in laminitis. Journal of Nutrition. 2006;136:2094S-2098S.

47. Bergman RN, Phillips LS, Cobelli C. Physiologic evaluation of factors controlling glucose tolerance in man. Journal of clinical investigation. 1981;68:1456-1467.

48. Toffolo G, Bergman RN, Finegood DT, Bowden CR, Cobelli C. Quantitative estimation of B-cell sensitivity to glucose in the intact organism; a minimal model of insulin kinetics in the dog. Diabetes. 1980;29:979-990.

49. George LA, Staniar WB, Treiber KH, Harris PA, Geor RJ. Insulin sensitivity ang glucose dynamics during pre-weaning foal development and in response to maternal diet composition. Domestic Animal Endocrinology, 37:2329. 2009.

50. Bergman RN, Ider YZ, Bowden CR, Cobelli C. Quantitative estimation of insulin sensitivity. American Journal of Phsiology. 1979;236:E667-E677.

51. Bergman RN. The minimal model; Yesterday, today and tomorrow. 1997; The minimal model approach and determinants of glucose tolerance, Louisiana State University:3-50.

52. Fowden AL, Gardner DS, Ousey J, Giussani DA, Forhead AJ. Maturation of pancreatic beta cell function in the fetal horse during late gestation. Journal of Endocrinology. 2005;186:467-473.

53. Fowden Al, Barnes RJ, Comline RS, Silver M. Pancreatic beta cell function in the fetal foal and mare. Journal of Endocrinology. 1980;87:293-301.

54. Fowden AL, Ellis L, Rossdale PD. Pancreatic beta cell function in the neonatal foal. Journal of Reproduction and Fertility. 1982;32:529-535.

55. Smyth GB, Young DW, Duran SH. Maturation of insulin and glucose responses to normal feeding in foals. Australian Veterinary Journal. 1993;70:129132.

56. Fink RI, Kolterman OG, Griffin J, Olefsky Jm. Mechanism of insulin resistance in ageing. Journal of Clinical Investigation. 1983;71:1523-1535.

57. Rowe JW, Minaker KL, Pallotta Ja, Flier JS. Characterization of the insulin resistance in ageing. Journal of Clinical Investigation. 1983;71:1581-1587.

58. Murphy D, Reid SWJ, Love S. The effect of age and diet on the oral glucose test in ponies. Equine Veterinary Journal. 1997;29:467-470.

59. Malinowski K, Betros CL, Flora L, Kearns CF, McKeever KH. Effect of training on age related changes in plasma insulin. Equine Exercise physiology:Equine Veterinary Journal Supplement. 2002. 34:147-153. 
60. Mehring JS, Tyznik WJ. Equine glucose tolerance. Journal of Animal Science. 1970;30:764-766.

61. Putten JPM, Wieringa TJ, Krans HMJ. Corticosteroids as long-term regulators of the insulin effectiveness in mouse $3 \mathrm{~T} 3$ adipocytes . Diabetologia. $1985 ; 28: 445-451$.

62. Jeffcott LB, Field JR. Glucose tolerance and insulin sensitivity in ponies and Standardbred horses. Equine Veterinary Journal. 1986;18:97-101.

63. Rijnen KE, van der Kolk JH. Determination of reference range values indicative of glucose metabolism and insulin resistance by use of glucose clamp techniques in horses and ponies. American Journal of Veterinary Research. 2003;64:1260-1264.

64. Asplin KE, Sillence MN, Pollitt CC, McGowan CM. Induction of laminitis by prolonged hyperinsulinemia in clinically normal ponies. Veterinary Journal. 2007;174 530-535.

65. Annandale EJ, Valberg SJ, Mickelson JR, Seaquist ER. Insulin sensitivity and skeletal muscle glucose transport in horses with equine polysaccharide storage myopathy. Neuromuscular Disorders. 2004;14:666-674.

66. Firshman AM, Baird JD, Hunt L, Valberg SJ. Hyperinsulinemic euglycemic clamping and insulin sensitivity in Belgian Draft Horses with poly saccharide storage myopathy. Proceedings of the American College of Veterinary Internal Medicine. 2006; Abstract 120.

67. Schmidt SL, Hickey MS. Regulation of insulin action by diet and exercise. Journal of Equine Veterinary Science. 2009. 29;274-284.

68. Baron AD, Laasko M, Bretchel G, Edelman SV. Reduced capacity and affinity of skeletal muscle for insulin-mediated glucose uptake in noninsulindependent diabetic subjects: effects of insulin therapy. Journal of Clinical Investigation. 1991;87:1186-1194.

69. Johnson PJ. The equine metabolic syndrome peripheral Cushing's syndrome. Veterinary Clinic North American Equine Practice. 2002;18:97-101.

70. Powell DM, Reedy SE, Sessions DR, Fitzgerald BP. Effect of short-term exercise training on insulin sensitivity in obese and lean mares. Equine Veterinary Journal Supplement. 2002;34:81-84.

71. Garcia MC, Beech J. Equine intravenous glucose tolerance test: Glucose and insulin response of healthy horses fed grain or hay and of horses with pituitary adenoma. American Journal of Veterinary Research.1986;47:570-572.

72. Bailey SR, Menzies-Gow NJ, Harris PA, Habershon-Butcher JL, Crawford C, Berhane Y, Boston RC, Elliot J. Effect of dietary fructans and dexamethazone administration on the insulin response of ponies predisposed to laminitis. Journal of American Veterinary Medical Associates. 2007;231:13651373. 
73. Robertson RP. Chronic oxidative stress as a central mechanism for glucose toxicity in pancreatic islet beta cells in diabetes. Biology and Chemistry. 2004;279:42351-42354.

74. Holland JL, Kronfeld DS, Meacham TN. Behavior of horses is affected by soy lecithin and corn oil in the diet. Journal of Animal Science 1996;74:12521255.

75. Oldham S, Potter GD, Evans JW, Smith SB, Taylor TS, Barnes WS. Storage and mobilization of muscle glycogen in exercising horses fed a fat supplemented diet. Journal of Equine Veterinary Science. 1990;10:353-359.

76. Holland JL, Kronfeld DS, Meacham TN. Behavior of horses is affected by soy lecithin and corn oil in the diet. Journal of Animal Science 1996;74:12521255.

77. Flakoll PJ, Wentzel LS, Rice DE, Hill JO, Abumrad NN. Short term regulation of insulin-mediated glucose utilization in four-day fasted human volunteers: role of amino acid availability. Diabetologia. 1992;35:357-366.

78. Krebs M, Krssak M, Bernroider E, Anderwald C, Brehm A, Meyerspeer $\mathrm{M}$, et al. Mechanism of amino acid-induces skeletal muscle insulin resistance in humans. Diabetes. 2002;51:599-605.

79. Tessari P, Inchiostro S, Biolo G, Duner E, Nosadini R, Tiengo A, et al. Hyperaminoacidemia reduces insulin-mediated glucose disposal in healthy man. Diabetologia. 1985;28:870-872.

80. Abumrad NN, Robinson RP, Gooch BR, Lacy WW. The effect of leucine infusion on substrate flux across the human forearm. Journal of Surgical Research. 1982;32:453-463.

81. Tremblay F, Gagnon A, Veilleux, Sorisky A, Marette A. Activation of the mTOR pathway acutely inhibits insulin signaling to Akt and glucose transport in 3T3-L1 and human adipocytes. Endocrinology. 2004;146:1328-1337.

82. NRC. Nutrient Requirements of horses. 6th ed. National Academy Press, Washington DC. 2007.

83. Williams CA, Kronfeld DS, Staniar WB, Harris PA. Plasma glucose and insulin responses of Thoroughbred mares fed a meal high in starch and sugar or fat and fiber. Journal of Animal Science 2001. 79;2196-2201.

84. Clark LL, Roberts MC, Argenzio RA. Feeding and digestive problems in horses. Veterinary Clinics of North America; Equine Practice. 1990;6:433-450.

85. Stull CL, Rodick AV. Responses of blood glucose, insulin and cortisol concentrations to common equine diets. Journal of Nutrition. 1987;118:206-213.

86. Pagan JD, Harris PA, Kennedy MAP, Davidson N, Hoekstra KE. Feed type and intake effects glycemic response in Thoroughbred horses. Proceedings $16^{\text {th }}$ Equine Nutrition and Physiology Symposium 1999;149-152. 
87. Pruett EDR, Oseid S. Effect of exercise on glucose and insulin response to glucose infusion. Scandinavian Journal of Clinical Laboratory Investigation. 1970;26:277-285.

88. Bogardus C, Thuillex P, Ravussin E, Vasquez B, Narmigia M, et al. Effect of muscle glycogen depletion on in vivo insulin action in man. Journal of Clinical Investigation. 1983;72:1605-1610.

89. Richter EA, Mikines KJ, Galbo H, Kiens B. Effect of exercise on insulin action in human skeletal muscle. Journal of Applied Physiology. 1989;66:876885.

90. Devlin JT, Horton ES. Effects of prior high-intensity exercise on glucose metabolism in normal and insulin resistant men. Diabetes. 1985;34:434-439.

91. Devlin JT, Hirshman MF, Horton ES, Horton ED. Enhanced peripheral insulin and spanchic insulin sensitivity in NIDDM men after a single bout of exercise. Diabetes. 36;434-39.

92. Mikines KJ, Sonne B, Farrell PA, Tronier B, Galbo H. Effect of physical exercise on sensitivity and responsiveness to insulin in humans. American Journal of Physiology. 1988;254:E248-E259.

93. Chaveau MA, Kaufmann M. Experiences pour la determination du coefficient de l'active nutritive et respiratoire des muscles en repos et en travail. Comptes Rendus de l'Académie des Sciences. 1887;104:1126-1132.

94. Goldstein MS, Mullick V, Huddleston B, Levine R. Action of muscular work on transfer of sugars across cell barriers:comparison with action of insulin. American Journal of Physiology. 1953;173:212-216.

95. Huycke E, Kruhoffer P. Effects of insulin and muscular exercise upon the uptake of hexoses by the muscle cells. Acta Physiologica Scandanavia. 1955;34:231-249.

96. Goodyear LJ, Hirshman MF, Horton ES. Exercise induced translocation of skeletal muscle glucose transporters. American Journal of Physiology. 1991;261:E795-E799.

97. Goodyear LJ, Hirschman MF, Smith RJ, Horton ES. Glucose transporter number, activity and isoform content in plasma membranes of red and white skeletal muscle. American Journal of Physiology. 1991;261:E556-E561.

98. Roy D, Marette A. Exercise induces the translocation of GLUT4 to transverse tubules from an intracellular pool in rat skeletal muscle. Biochemistry and Biophysiology Research Communication. 1996;223:147-152.

99. Gao J, Ren J, Gulve EA, Hollosky JO. Additive effect of contractions and insulin on GLUT4 translocation into the sarcolemma. Journal of Applied Physiology. 1994;77:1597-1601.

100. Nesher R, Karl IE, Kipnis DM. Dissociation of the effects of insulin and contraction on glucose transport in rat epitrochlearis muscle. American Journal of Physiology. 1985;249:C226-232. 
101. Lund S, Holman GD, Schmitz O, Pederson O. Contraction stimulates translocation of glucose transporter GLUT4 in skeletal muscle through a mechanism distinct from that of insulin. Proceedings from the National Academy of the Sciences. USA. 1995;92:5817-5821.

102. Douen AG, Ramal T, Rastogi S, Bilan PJ, Cartee GD. Exercise induces recruitment of the "insulin responsive glucose transporter." Evidence for insulinand exercise-recruitable transporter pools in skeletal muscle. Journal of Biological Chemistry. 1990;265;13427-13430.

103. Richter EA, Garetto LP, Goodman MN, Ruderman NB. Muscle glucose metabolism following exercise in the rat: increased sensitivity to insulin. Journal of Clinical Investigation. 1982;69:785-793.

104. Douen AG, Ramal T, Rastogi S, Bilan PJ, Cartee GD. Exercise induces recruitment of the "insulin responsive glucose transporter." Evidence for insulinand exercise-recruitable transporter pools in skeletal muscle. Journal of Biological Chemistry. 1990;265;13427-13430.

105. Richter EA, Garetto LP, Goodman MN, Ruderman NB. Muscle glucose metabolism following exercise in the rat: increased sensitivity to insulin. Journal of Clinical Investigation. 1982;69:785-793.

106. Treadway JL, James DE, Burcel E, Ruderman NB. Effect of exercise on insulin receptor binding and kinase activity in rat skeletal muscle. American Journal of Physiology. 1989;256:E138-E144.

107. Bonen A, Tan MH, Watson-Wright WM. Effects of exercise on insulin binding and glucose metabolism in the muscle. Canadian Journal of Pharmacology. 1984;62:1500-1504.

108. Zorzano A, Balton TW, Garetto LP, Goodman MN, Ruderman NB. Muscle a-aminoisobutyric acid transport after exercise: enhanced stimulation by insulin. American Journal of Physiology: Endocrinology and Metabolism. 1985;248:546-552.

109. Cartee GD, Holloszy JO. Exercise increases susceptibility of muscle glucose transport to activation by various stimuli. American Journal of Physiology. 1990;258:E390-E393.

110. Azevedo JL Jr, Carey JO, Pories WJ, Morris PG, Dohm GL. Hypoxia stimulates glucose transport in insulin resistant human skeletal muscle. Diabetes. 1995;44:695-698.

111. Kim Y, Inoue T, Nakajima R, Nakae K, Tamura T. Effects of endurance training on gene expression of insulin signal transduction pathway. Biochemistry and Biophysiology Research Communication. 1995;210:766-773.

112. Holloszy JO, Hansen PA. Regulation of glucose transport into skeletal muscle. Review of Physiology, Biochemistry and Pharmacology. 1996;128:99103.

113. Anderson PH, Lund S, Schmitz O, Junker S, Kahn BB. Increased insulinstimulated glucose uptake in athletes: the importance of GLUT4 mRNA, GLUT4 protein and fiber type composition of skeletal muscle. Acta Physiologica Scandinavia. 1993;149:393-404. 
114. Hughes VA, Fiatarone MA, Fielding Ra, Kahn BB, Ferrara CM. Exercise increases muscle GLUT4 levels and insulin action in subjects with impaired glucose tolerance. American Journal of Physiology, Endocrinology and Metabolism. 1993;264:E855-E862.

115. Coenen M. About the predictability of oxygen consumption and energy expenditure in the exercising horse. Proceedings of the $19^{\text {th }}$ Equine Science Society., Tuscon, AZ. 2005:123.

116. St-Pierre J. Mitochondria on the Rocks. The Journal of Experimental Biology:2004. 207: v.

117. Williams CA, Kronfeld DS, Hess Tm, Saker KE, Waldron JN, Crandell

KM, Hoffman RM, Harris PA. Antioxidant supplementation and subsequent oxidative stress of horses during an $80-\mathrm{km}$ endurance race. Journal of Animal Science. 2004;82:588-594.

118. Kearns, DR. Physical and chemical properties of singlet molecular oxygen. Chemical Reviews. 1971;71:395-427.

119. Ji LL. Modulation of skeletal muscle antioxidant defense by exercise: Role of redox signaling. Free Radical Biology and Medicine: 2008. 44:142-152.

120. Powers SE, Talbert EE, Adhihetty P. Reactive oxygen and nitrogen species as intracellular signals in skeletal muscle. Journal of Applied Physiology: 2011. 859: 2129-2138.

121. Kahn N, Swartz H. Measurements in vivo of parameters pertinent to ROS/RNS using EPR spectroscopy. Molecular and Cellular Biochemistry: 2002. 234-235: 341-347.

122. Shulaev V, Oliver DJ. Metabolic and proteomic markers for oxidative stress. New tools for reactive oxygen species research. Plant Physiology: 2006. 141:367-372.

123. Lagouge M, Argmann C, Herhart, Hines Z, Meziane H, et al. Resveratrol Improves Mitochondrial Function and Protects against Metabolic Disease by Activating SIRT1 and PGC-1 $\alpha$. Cell. 2 6;127: 11 -1122.

124. Das S, Khan N, Mukherjee S, Bagchi D, Gurusamy N, Swartz H, Das DK. Redox regulation of resveratrol-mediated switching of death signal into survival signal. Free Radicals in Biology and Medicine. 2008;44:82-90.

125. Wyke SM, Tisdale MJ. Induction of protein degradation in skeletal muscle by a phorbol ester involves upregulation of the ubiquitin-proteasome proteolytic pathway. Life Sciences. 2006;78;2898-2910.

126. Russel ST, Wyke SM, Tisdale MJ. Mechanism of induction of muscle protein degradation by angiotensin II. Cell Signaling. 2006;18:1087-1096.

127. Wyke SM, Russell ST, Tisdale MJ. Induction of proteasome expression in skeletal muscle is attenuated by inhibitors of NF-kappaB activation. British Journal of Cancer 2004;91:1742-1750.

128. Alarcon de la Lastra C,Villegas I. Review: Resveratrol as an antiinflammatory and anti-aging agent: Mechanisms and clinical implications. Molecular Nutrient Food Research. 2005;49:405-430.

129. Fremont L. MiniReview: Biological effects of resveratrol. Life Sciences. 2000;66:663-673. 
130. Stervbo U, Vang O, Bonnesen C. A review of the content of the putative chemopreventive phytoalexin resveratrol in red wine. Food Chemistry. 2007; 101:449-457.

131. Bertelli AA, Giovanni L, Bernini W, Migliori M, Fregioni M. Bavarescelo et al. Antiplatelet activity of cis-resveratrol . Drugs Under Experimental and Clinical Research. 1996;22:61-63.

132. Bertelli AAE, Giovanni L, Stradi R, Bertelli A, Tillment JP. Plasma, urine and tissue levels of trans- and cis- resveratrol (3,4',5-trihydroxystilbene) after short term or prolonged administration red wine to rats. International Journal on Tissue Reactions. 1996;XVIII:67-71.

133. Bertelli AAE, Giovanni L, Stradi R, Urien S, et al. Kinetics of trans- and cis-resveratrol $(3,4$ ',5-trihydroxystilbene) after red wine administration to rats. International Journal of Clinical Pharmacology Research. 1996;16:77-81.

134. Bertelli A, Bertelli AAE, Giozzioni A, Giovannis L. Plasma and tissue resveratrol concentrations and pharmacological activity. Durgs Under Exerimental and Clinical Research. 1998;XXIV:133-138.

135. Soleas GJ, Angelini M, Grass L, Diamandis EP, Goldberg DM. Absorption of trans-resveratrol in rats. Methods in Enzymology. 2001;335:145154.

136. Wenzel E, Somoza V. Review:Metabolism and bioavailability of transresveratrol. Molecular Nutrient Food Research. 2005;49:472-481

137. Goldberg DM, Yan J, Soleas GJ. Absorption of three wine-related polyphenols in three different matricies by healthy subjects. Clinical Biochemistry. 2003;36:79-87.

138. Belguendouz L, Fremont L, Linard A. Resveratrol inhibits metal iondependent and independent peroxidation of porcine low-density lipoproteins. Biochemical Pharmacology. 1997;53:1347-1355.

139. Jannin B, Menzel M, Berlot JP, Demal D, et al. Transport of resveratrol, a cancer chemopreventive agent, cellular targets: plasmatic protein binding and cell uptake. Biochemical Pharmacology. 2004;68:1113-1118.

140. Zunszain PA, Ghuman J, Komatsu T, Tsuchida E, Curry S. Crystal structural analysis of human serum albumin complexed with hemin and fatty acid. BMC Structural Biology. 2003;3: 6.

141. Belguendouz L, Fremont L, Gozzelino MT. Interaction of trans-resveratrol with plasma proteins. Biochemical Pharmacology. 1998;55:811-816.

142. Lancon A, Delmas D, Osman H, Thenot JP, et al. Human hepatic cell uptake of resveratrol: involvement of both passive and carrier mediated process. Biochemical and Biophysical Research Communications. 2004;316:1132-1137.

143. Asensi M, Medina I, Ortega A, Carretero J, et al. Inhibition of cancer growth by resveratrol is related to its low bioavailability. Free Radical Biology and Medicine. 2002;33:387-398.

144. Gescher AJ, Steward WP. Relationship between mechanisms, bioavailability and preclinical chemopreventive efficacy of resveratrol: a conundrum. Cancer Epidemiology Biomarkers and Prevention. 2003;12:953-957. 
145. Siemann EH, Creasy LL. Concentration of the phytoalexin resveratrol in red wine. American Journal of Enology and Viticulture. 1992;43:49-52.

146. Sun AY, Chen Ym, James-Kracke M, Wixom P, Cheng Y. EthanolInduced Cell Death by Lipid Peroxidation in PC12 cells. Neurochemistry Research. 1997;8:1499-1502.

147. Fauconneau B, Waffo-Teguo P, Huguet F, Barrier L, Decendit A Merillon JM. Comparative study of radical scavenger and antioxidant properties of phenolic compounds from Vitis vinifera cell cultures using in vitro tests. Life sciences. 1997;22:1187-1192.

148. Kawada N, Seki S, Inoue M, Kuroki T. Effect of antioxidants, resveratrol, quercetin, and $\mathrm{N}$-acetylsysteine on functions of cultured rate hepatic stellate cells and kupffer cells. Hepatology. 1998;27:1265-1274.

149. Benton CR, Holloway GP, Han XX, Yoshida Y, Snook LA, Lally J, Glatz JFC, Luiken JJ, Chabowski A, Bonen A. Increased levels of peroxisiome proliferators-activated receptor gamma, coactivator 1 alpha improve lipid utilization, insulin signaling, and glucose transport in skeletal muscle of lean and insulin resistant obese Zucker rats. Diabetologia; 2010;53:2008-2019.

150. Palsamy P, Subramanian S. Modulatory effects of resveratrol on attenuating the key enzymes activities of carbohydrate metabolism in streptozotocin-nicotinamide-induced diabetic rats. Chemico-biological Interactions. 2009;179:356-362.

151. Karlsson KR, Zierath JR, Krook S, Lienhard GE, Wallberg-Henriksson G. Insulin-Stimulated Phosphorylation of the Akt Substrate AS160 Is Impaired in Skeletal Muscle of Type 2 Diabetic Subjects Diabetes:2005;54:1692-1697.

152. Lagouge M, Argmann C, Gerhart-Hines Z, Meziane H, Lerin C, Daussin $\mathrm{F}$, et al. Resveratrol imporves mitochondrial function and protects against metabolic disease by activating SIRT1 and PGC-1 $\alpha$. Cell. 2006;127:1109-1122.

153. Robb EL, Page MM, Wiens B, Stuart JA. Molecular mechanisms of oxidative stress resistance induced by resveratrol: Specific and progressive induction of MnSOD. Biochemical and Biophysical Research Communications. 2008;367:406-412.

154. Gusman J, Malonne H, Atassi G. A reappraisal of the potential chemopreventive and chemotherapeutic properties of resveratrol. Carcinogenesis. 2001;22:111-1117.

155. Chong Y, Shin YG, Chow A, Yongmei L, Kosmeder JW, Lee YS, Hirschelman WH, Pezzuto JM, Mehta RG, van Breemen RB. A human, rat and mouse metabolism of resveratrol. Pharmaceutical Research. 2002;19:1907-1914.

156. Ogden CL, Fryar CD, Carrol MD, Flegal KM. Mean body weight, height, and body mass index, United States. Division of Health and Nutrition Examination Surveys. 2004.

157. S. S. Eivers, B. A. McGivney, R. G. Fonseca, D. E. MacHugh, K. Menson, S. D. Park, J.-L. L. Rivero, C. T. Taylor, L. M. Katz, and E. W. Hill Alterations in oxidative gene expression in equine skeletal muscle following exercise and training. Physiolgical Genomics. 2010;40(2):83-93. 
158. Nielsen BD, O'Connor-Robinson CI, Spooner HS, Shelton J. Glycemic and Insulin Responses are Affected by Age of Horse and Method of Feed Processing. Journal of Equine Veterinary Science. 2010;30:249-258.

159. Spooner, HS. Hydration status of endurance horses as affected by dietary fiber type with and without supplemental fat. Michigan State University, Doctorate Dissertation, 2008; 3348222.

160. Kim SJ, Lee YH, Han MD, Mar W, Kim WK, Nam KW. Resveratrol, Purified from the Stem of Vitis coignetiae Pulliat, Inhibits Food Intake in C57BL/6J Mice. Archives of Pharmacal Research. 2010;33:775-780.

161. White A, Estrada M, Walker K, Wisnia P, Filgueria G, Valdes F, Arandea $\mathrm{O}$, Behn C, Martinez R. Role of exercise and ascorbate on plasma antioxidant capacity in Thoroughbred racehorses. Comparative Biochemistry and Physiology. 2001;128:99-104.

162. Sen CK. Oxidants and antioxidants in exercise. Journal of Applied Physiology. 1995;79:675-686.

163. Kanter MM. Free radicals, exercise and antioxidant supplementation. International Journal of Sports Nutrition. 1994;4:205-220.

164. Sen Ck, Goldfarb AH. Antioxidants and physical exercise. In: Handbook of Oxidants and Antioxidants in Exercise. Elsevier, Amsterdam, The Netherlands. 1999:297-322.

165. Davies KJA, Quintanilha AT, Brooks GA, Packer L. Free radicals and tissue damage produced by exercise. Biochemical and Biophysiological Research Comunications. 1982;107:1198-1205.

166. Maughan RJ, Donnelly AE, Gleeson M, Whiting PH, Walker KA, Clough PJ. Delayed-onset muscle damage and lipid peroxidation in man after a downhill run. Muscle Nerve. 1989;12:332-336.

167. Viinikka L, Vuori J, Ylikorkala O. Lipid peroxides, prolactin, and thromboxane A2 in runners during acute exercise. Medicine Science and Sport. 1984;16:275-277.

168. Liu ML, Bergholm R, Makimattila S, Lahdenpera S, Valkonen M, Hilden $\mathrm{H}$, Yki-Jarven $\mathrm{H}$, Tanskinen M. A marathon run increases the susceptibility of LDL to oxidation in vitro and modifies plasma antioxidants. American Journal of Physiology. 1999;276:1083-1091.

169. Kaikkonen J, Kosonen L, Nyyssonen K, Porkkala-Sarataho E, Salonen R, Korpela H, Salonen JT. Effect of combined coenzyme Q10 and D- $\alpha$-tocopherol acetate supplementation on exercise-induced lipid peroxidation and muscular dmage: a placebo-controlled double-blind study in marathon runners. Free Radical Research. 1998;29:85-92.

170. Laaksonen DE, Atalay M, Niksanen L, Uusitupa M, Kanninen O, Sen CK. Blood glutathione homeostasis as a determinant of resting and exercise-induced oxidative stress in young men. Redox Research. 1999;4:38-43.

171. Rokitzki L, Logemann E, Sagredos AN, Murphy M, Wetzel-Roth W, Keul J. Lipid peroxidation and antioxidative vitamins under extreme endurance stress. Acta Physiologia Scandanavia. 1994;151:149-158. 
172. Ortenblad N, Madsen K, Djurhuus M. Antioxidant status and lipid peroxidation adter short term maximal exercise in trained and untrained humans. The American Physiological Society. 1997:R1258-R1263.

173. Alessio HM, Goldfarb AH, Cutler RG. MDA content increases in fast- and slow-twitch skeletal muscle with intensity of exercise in a rat. American Journal of Physiology. 1988;255:C874-C877.

174. Ji LL, Stratman FW, Lardy HA. Antioxidant enzyme systems in rat liver and skeletal muscle; influences of selenium deficiency, chronic training and acute exercise. Archives of Biochemicals and Biophysiology. 1988;263:150-160.

175. Al-Qudah KM, Al-Majali AM. Status of biochemical and antioxidant variables in horses before and after long distance race. Revue de Médecine Vétérinaire. 2006;157:307-312. 


\section{VITA}

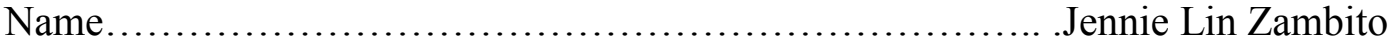

Birthplace................................................Red Bank, NJ

Date of Birth................................................... . 1987

Parents.................................................... Edward A. Zambito

Linda J. Zambito

Schools Attended:

Monsignor Donovan High School ........................ 2001 - 2005

Toms River, NJ

Rutgers University, Cook College .....................2005 - 2009

New Brunswick, NJ

Degrees Received

Bachelor of Science in Animal Science; Pre-veterinary/Research, and Equine Science Options

Rutgers University, 2009 
Effects of Resveratrol Supplementation on Glycemic Response and Oxidant Status in Moderately Exercised Aged Quarter Horse Geldings

Jennie L. Zambito

Thesis submitted to the

Davis College of Agriculture, Natural Resources and Design

at West Virginia University

in partial fulfillment of the requirements

for the degree of

Master of Science

in

Animal and Nutritional Sciences

Department of Animal and Nutritional Science

APPROVAL OF THE EXAMINING COMMITTEE

Holly S. Spooner, Ph. D, Chair

Eugene E. D. Felton, Ph. D

Janet Tou, Ph. D

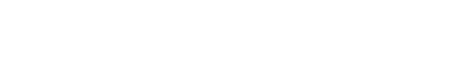

